\title{
Human Endogenous Retroviruses as Gene Expression Regulators: Insights from Animal Models into Human Diseases
}

\author{
Serpen Durnaoglu ${ }^{1,2}$, Sun-Kyung Lee $e^{1,2, *}$, and Joohong Ahnn ${ }^{1,2, *}$
}

\begin{abstract}
${ }^{1}$ Department of Life Sciences, College of Natural Sciences, Hanyang University, Seoul 04763, Korea, ${ }^{2}$ Research Institute for Natural Sciences, College of Natural Sciences, Hanyang University, Seoul 04763, Korea

*Correspondence: sunkyung|@hanyang.ac.kr (SKL); joohong@hanyang.ac.kr (JA)

https://doi.org/10.14348/molcells.2021.5016
\end{abstract}

www.molcells.org

The human genome contains many retroviral elements called human endogenous retroviruses (HERVs), resulting from the integration of retroviruses throughout evolution. HERVs once were considered inactive junk because they are not replication-competent, primarily localized in the heterochromatin, and silenced by methylation. But HERVs are now clearly shown to actively regulate gene expression in various physiological and pathological conditions such as developmental processes, immune regulation, cancers, autoimmune diseases, and neurological disorders. Recent studies report that HERVs are activated in patients suffering from coronavirus disease 2019 (COVID-19), the current pandemic caused by SARS-CoV-2 (severe acute respiratory syndrome coronavirus 2 ) infection. In this review, we describe internal and external factors that influence HERV activities. We also present evidence showing the gene regulatory activity of HERV LTRs (long terminal repeats) in model organisms such as mice, rats, zebrafish, and invertebrate models of worms and flies. Finally, we discuss several molecular and cellular pathways involving various transcription factors and receptors, through which HERVs affect downstream cellular and physiological events such as epigenetic modifications, calcium influx, protein phosphorylation, and cytokine release. Understanding how HERVs participate in various physiological and pathological processes will help develop a strategy to generate effective therapeutic approaches targeting HERVs.
Keywords: cancer, COVID-19, human endogenous retrovirus, neurological disease, syncytin-1, toll-like receptor

\section{INTRODUCTION}

Endogenous retroviruses (ERVs) are found in the genomes of all vertebrates and are therefore considered remnants of ancestral infections (Dewannieux and Heidmann, 2013; Hayward et al., 2015). Since many different species can share endogenous retroviral sequences, exogenous retrovirus might have infected common ancestors and gotten fixed in the genome before species diverged or been later spread via a cross-species transmission (Hayward et al., 2013) (Supplementary Fig. S1). Human endogenous retroviruses (HERVs) were first discovered more than 40 years ago by screening human tissue with non-stringent blot hybridization probes derived from murine leukemia virus (MuLV), revealing the presence and cloning of the first endogenous retroviral sequences present in human DNA (Escalera-Zamudio and Greenwood, 2016; Martin et al., 1981). HERVs and their derivative sequences comprise at least $8 \%$ of the human genome (Mager and Medstrand, 2005). While a majority of these sequences are mostly defective, several phylogenetically distinct HERVs are still transcriptionally active and competent to produce some retroviral proteins (Bannert and Kurth,

Received 4 December, 2021; revised 6 December, 2021; accepted 7 December, 2021; published online 27 December, 2021 
2004; Chan et al., 2019; Ovejero et al., 2020; Zhang et al., 2019b). Many studies provide evidence that HERVs influence a variety of physiological properties, including pluripotency of stem cells, cell proliferation, and cell survival. Faulty regulation of HERV activities can lead to human illness, including various cancers and neurological disorders. For example, increased expression of HERV envelope protein (ENV) contributes to the onset of amyotrophic lateral sclerosis (ALS), autistic spectrum disorder (ASD), and fibromyalgia (FM), as well as leukemia, germline tumors, and pancreas cancer (Frank et al., 2005; Gao et al., 2021; Kristensen and Christensen, 2021; Wang et al., 2014). HERVs can be involved in oncogenesis in various ways, such as insertional mutagenesis or chromosomal instability due to their retrotransposition ability (Burns, 2017). The loss of CpG methylation in cancers appears to influence retrotransposon elements, particularly HERVs, in a preferential manner (Kassiotis, 2014). CpG hypomethylation also affects HERV expression in autoimmune diseases (Nakkuntod et al., 2013; Okada et al., 2002; Wang et al., 2019). Moreover, the long terminal repeats (LTRs) of HERVs affect gene expression by interacting with a variety of endogenous transcription factors, influencing biological processes such as early embryogenesis (Fuentes et al., 2018) or innate immunity (Chuong et al., 2016). Elevated transcription driven by HERV LTRs can disrupt neuronal differentiation, which indicates that HERV activation may play a critical role in brain development (Padmanabhan Nair et al., 2021). LTR-overlapping transcripts specific in certain cancers raises the possibility that the highly predictable transcripts can provide disease prognosis and information of cancer-specific antigenicity (Attig et al., 2019). Recently, the infectious disease COVID-19 has been reported to modulate the expression of some HERV genes, and HERV promoter activities are retained in some non-human animal models (Balestrieri et al., 2021; Casau et al., 1999; Durnaoglu et al., 2020; Garcia-Montojo and Nath, 2021; Levet et al., 2017; Pi et al., 2004; Tanaka et al., 2003; Tovo et al., 2021). In this review, we summarize various modes of HERV activation and their interacting molecular components and regulatory signaling networks. We also address their functional roles in human physiology and the pathogenesis of the related diseases. Research utilizing various animal models studying HERV activation provides insights regarding perspective roles of HERVs. Finally, we also discuss a potential therapeutic HERV-DNA vaccine against novel diseases such as COVID-19.

\section{HERVs IN DISEASES}

HERVs involve in the pathology of various diseases, including cancers (Burns, 2017; Fischer et al., 2016; Gao et al., 2021; Kassiotis, 2014; Mullins and Linnebacher, 2012; Yu et al., 2013), autoimmune diseases (Anand et al., 2017; Balada et al., 2009; Brodziak et al., 2012; Nelson, 1995; Tugnet et al., 2013) and neurological diseases (Antony et al., 2011; Giménez-Orenga and Oltra, 2021; Gröger et al., 2021). The important topics have been extensively reviewed elsewhere (Garcia-Montojo et al., 2018; Hohn et al., 2013). Many studies report that transcripts and products of HERVs are detected in various cancers; breast cancers, ovarian cancers (Wang-Johanning et al., 2007), lymphoma (Contreras-Galindo et al.,
2008), melanoma (Serafino et al., 2009), germline tumors (Herbst et al., 1996), leukemia (Depil et al., 2002), prostate cancer (Goering et al., 2011), and colon cancer (Dolci et al., 2020). HERVs are also involved in the development of autoimmune diseases such as multiple sclerosis (MS) (Garson et al., 1998; Komurian-Pradel et al., 1999; Rasmussen et al., 1995), rheumatoid arthritis (RA) (Freimanis et al., 2010; Mameli et al., 2017; Nakagawa et al., 1997), systemic lupus erythematosus (SLE) (Blomberg et al., 1994), as well as neurological diseases such as ALS (Li et al., 2015; Mayer et al., 2018), ASD (Balestrieri et al., 2012; 2019), attention deficit hyperactivity disorder (ADHD) (Anand et al., 2017; Cipriani et al., 2018; D'Agati et al., 2016), FM (Ovejero et al., 2020; Rodriguez-Pintó et al., 2014), schizophrenia (Huang et al., 2011; Karlsson et al., 2004; Perron et al., 2008; 2012), and bipolar disorder (BD) (Fries et al., 2019; Giménez-Orenga and Oltra, 2021; Goldsmith et al., 2016; Perron et al., 2012). This is likely to a continuing and growing list of diseases in which HERVs are involved in the pathology.

\section{REGULATORY FACTORS FOR HERVs}

HERV LTRs harbor sequences acting as a promoter, and they can alter the expression of nearby cellular genes (Dunn et al., 2003; Lamprecht et al., 2010; Lee et al., 2020a; Mullins and Linnebacher, 2012). Also, cellular activities can be changed by RNAs or proteins that are produced from transcription and translation of HERV sequences (Denne et al., 2007). Therefore, it is critical to control HERV activities throughout human life adequately. There are external, internal, and epigenetic factors that can directly or indirectly interfere with the regulatory processes mediated by HERVs (Fischer et al., 2016).

\section{External factors: UV, smoking, infections, and chemicals}

UV radiation, especially UVB and UVC, stimulates transcription of retroviral env and pol genes of HERV-K in melanoma (Reiche et al., 2010; Schanab et al., 2011) and keratinocyte cell lines (Hohenadl et al., 1999), which suggests that HERV-K may specifically contribute to UV radiation-related pathogenesis of skin cells. Smoking also affects the expression of HERVs, because the level of HERV-derived transcripts is higher in smokers than in non-smokers (Bergallo et al., 2019; Gabriel et al., 2010; Wallace et al., 2014).

Infection of parasites such as Toxoplasma gondii is also reported to upregulate transcription of certain HERV elements in human neuroepithelial cells (Frank et al., 2006). Viral infections by Epstein-Barr virus (EBV) (Sutkowski et al., 2004), human immunodeficiency virus 1 (HIV-1) (Contreras-Galindo et al., 2007), herpes simplex virus 1 (HSV-1) (Lee et al., 2003), coxsackievirus-B4 (CV-B4) (Dechaumes et al., 2020), Kaposi's sarcoma-associated herpesvirus (KSHV) (Dai et al., 2018), dengue virus serotype 2 (DENV-2) (Wang et al., 2020a), cytomegalovirus (CMV) (Bergallo et al., 2015), human herpesvirus 6B (HHV-6B) (Turcanova et al., 2009), or influenza A (Nellåker et al., 2006) have been shown to increase the level of transcripts from diverse classes of HERVs. Recently, HERV-W Env is reported to be highly expressed in the leukocytes of COVID-19 patients infected by SARS-CoV-2 (Balestrieri et al., 2021). 
Chemical elements such as hydroquinone (HQ) (Conti et al., 2016), cupric ion (Karimi et al., 2019), and silver nanoparticles (Alqahtani et al., 2016) are found to influence the expression of HERVs $(\mathrm{H}, \mathrm{K}$, and $\mathrm{W})$ in several tumor cell lines. $\mathrm{HQ}$ is a benzene-derived metabolite that is connected with the risk of acute myelogenous leukemia. After treatment with $\mathrm{HQ}$, three human retrotransposons, long interspersed element 1 (LINE-1, L1), alu and syncytin-1, the HERV-W ENV protein, display increased expression levels in monocytic leukemia cell line THP-1 and hematopoietic stem cells (Conti et al., 2016). Upon copper sulfate $\left(\mathrm{CuSO}_{4}\right)$ exposure, the expression of HERV-H env is decreased, whereas that of env genes of HERV-K and HERV-W is increased in human skin malignant melanoma cell line SK-MEL-37. However, the expression of both HERV-K and HERV-W env genes seems to decrease as the concentration of $\mathrm{CuSO}_{4}$ increases (Karimi et al., 2019). Finally, silver nanoparticles (AgNPs) increase mRNA and protein levels of syncytin-1 of HERV-W in both human T-lymphoblastic leukemia MOLT-4 and Fanconi anemia acute myeloid leukemia (FA-AML1) cells (Alqahtani et al., 2016).

\section{Internal factors: morphogens, hormones, and cytokines}

Retinoic acid, a vitamin A metabolite that functions as a morphogen (Ono et al., 1987) during early embryogenesis, is also reported to transcriptionally activate retinoic acid-responsive human ERV-I (RRHERV-I), a type of HERV-I, in teratocarcinoma cells (Kannan et al., 1991). HERV-K expression is stimulated by a sequential treatment of female hormones, progesterone after estradiol, in human breast cancer cell line T47D (Ono et al., 1987). On the other hand, HERV-R expression in human vascular endothelial cells is upregulated by treatment of various cytokines such as tumor necrosis factor-alpha (TNF- $\alpha$ ), interleukin-1 alpha (IL-1 $\alpha)$ and IL-1 $\beta$, but downregulated by that of interferon-gamma (IFN $\gamma$ ) (Katsumata et al., 1999). These observations indicate that HERV-R expression may be up-or down-regulated at sites of inflammation in human vessels and play a role in inflammatory vascular diseases. Various transcription factors and cellular signaling pathways are downstream of these internal factors and discussed below.

\section{Epigenetic factors: DNA methylation and histone modifi- cation}

Transcription of HERV-K and methylation level of their LTRs are associated with each other in the teratocarcinoma cells (Florl et al., 1999). DNA demethylation of HERV LTRs triggers upregulation of HERV expression. A low level of DNA methylation in HERV-K and - $\mathrm{W}$ regions has been reported in urothelial cell carcinoma (UCC) (Menendez et al., 2004) and ovarian cancer (Stengel et al., 2010). HERVs harbor binding sequences for KRAB-containing zinc finger proteins (KRAB-ZFPS), and histone modifications are induced by the interaction of KRAB-ZFPs to those binding sites. KRAB-ZFPs bind to transcription factor binding site (TFBS) within HERV elements, recruiting the co-repressor KRAB-associated protein 1 (KAP1), which is also called TRIM28 (Giménez-Orenga and Oltra, 2021). In another study, it is shown that HERV-K is repressed by KAP1 (TRIM28) in undifferentiated human embryonic stem cells (hESCs) and differentiated cell lines HeLa and 293T cells, adult peripheral blood mononuclear cells (PBMCs), and CD4 ${ }^{+} T$ cells (Tie et al., 2018). HERV-S and HERV -T are overexpressed in KAP1 (TRIM28) knockout HeLa cells, and the KAP1 (TRIM28) depletion also results in a decrease in H3K9me3 level at HERV-K regions, which supports KAP1 (TRIM28)'s repression on HERVs. These results indicate that the KRAB-ZFP/KAP1 (TRIM28) pathway involves regulating HERV activation presumably via epigenetic controls. Knockdown of KAP1 (TRIM28) in human neural progenitor cells (NPCs) generally upregulates various HERV gene expressions (Brattås et al., 2017). A gene regulatory network based on HERVs may participate in the control of gene expression of protein-coding transcripts necessary for proper development of nervous systems (Lee et al., 2019b; 2021b; Zhang et al., 2019a).

CRISPR/Cas9-based deletion of KAP1 (TRIM28), an epigenetic co-repressor protein, results in upregulation of ERVs in mouse NPCs in vitro (Jönsson et al., 2021). However, there is no activation of ERVs in adult neurons, in case a vector targeting KAP1 (TRIM28) is injected into the forebrain of adult Cas9-GFP mice (Lee et al., 2020b). KAP1 (TRIM28) is required to silence ERVs during brain development in both humans and mice, and the results indicate that the suppression of ERVs by KAP1 (TRIM28) remains in the adult brain. In vivo depletion of KAP1 (TRIM28) in cortical NPCs during mouse brain development later results in upregulation of ERVs in excitatory neurons in the adult brain. In addition, activated microglia are found in the cortex where excitatory neurons lack KAP1 (TRIM28). Expression of ERV in neurons is linked to the activation of microglia, which demonstrates that activation of ERV in neurons results in an inflammatory response in the nervous system.

TIP60 is a histone acetyltransferase and functions as a haploinsufficient tumor suppressor (Gorrini et al., 2007). Tumors from colorectal and breast cancer patients show a decrease in the expression of TIP60, suggesting a link between downregulation of TIP60 and tumor progression (Gorrini et al., 2007; Mattera et al., 2009). TIP60 positively regulates the expression of histone methyltransferases (HMTs), SETDB1, and SUV39H1, loss of TIP60 results in a global decrease in H3K9me3 level (Rajagopalan et al., 2018). TIP60 silences HERV-L, HERV-K, HERV-1, and HERV-W, dependent on bromodomain-containing protein 4 (BRD4), an epigenetic reader recognizing histone proteins (Zhou et al., 2020), through regulation of histone $\mathrm{H} 3 \mathrm{~K} 9 \mathrm{me} 3$ in colorectal cancer cells. HERVs are repressed in colorectal cells overexpressing TIP60. In addition, the nonobese diabetic/severe combined immunodeficient (NOD-SCID) mouse model, which is injected with colorectal cancer cells overexpressing TIP60, exhibits a reduction in tumor growth. ChIP assay reports TIP60 occupancy at LTR regions of HERVs (Rajagopalan et al., 2018).

\section{HERVs IN TRANSGENIC ANIMAL MODELS}

HERVs can regulate the expression of host cellular genes through their cis-regulatory elements predominantly localized in their LTRs. These features play a critical role in the commencement and progression of diseases in several ways involving genetic instability, hypomethylation, transactivation, 
and RNA interference (Yu et al., 2013). Thus, it is crucial to understand how LTRs participate in gene expression processes. Utilizing animal models provides research platforms to test LTR activities and their interacting factors in various contexts, thereby helping understand the potential roles of LTR in human physiological and pathological conditions (Fig. 1).

\section{Caenorhabditis elegans}

C. elegans is a free-living, non-parasitic, and transparent nematode about $1 \mathrm{~mm}$ in length. $C$. elegans is the first multi-cellular organism and animal to have its whole genome sequenced, and its genome contains approximately 20,000 genes and shares high genetic homology of $60 \%$ to $80 \%$ with humans (C. elegans Sequencing Consortium, 1998). C. elegans is a versatile model with a powerful genetics due to many advantages such as easy lab maintenance, a large brood size with approximately 300 offspring within a reproductive cycle of only three days and the short lifespan of three weeks in a typical culture condition, and practically no ethical concerns (Meneely et al., 2019). Therefore, C. elegans has been widely used to study various questions asking principles in biological sciences and human diseases (Chung et al., 2020; Kim et al., 2019; Lee et al., 2021a; Levine and Lee, 2020).
Promoter activity of HERV-K LTR that is assessed by expressing GFP is reported in free-living soil worms $C$. elegans (Durnaoglu et al., 2020). Expression of GFP is mainly observed in vulval muscle, and LTR activation is dependent on che-1, a sensory neuron driver, and lin-15b, a negative regulator of RNAi and germline gene expression. CHE-1 is a $\mathrm{C} 2 \mathrm{H} 2$ zinc-finger transcription factor and has various homologs detected in human, murine, and fly genomes. The GLASS transcription factor required for photoreceptor cell differentiation in Drosophila melanogaster and human ZNF500 shares the highest homology with the CHE-1 domain (Etchberger et al., 2007; Moses et al., 1989; Uchida et al., 2003).

\section{Drosophila melanogaster}

The fruit fly, D. melanogaster, has been used as a genetic model organism for over a century to study various biological processes such as inheritance, embryonic development, and aging (Jennings, 2011). Drosophila can be easily cultured in a laboratory condition, have a short life cycle of around ten days at $25^{\circ} \mathrm{C}$, a large number of laid eggs, approximately 100 eggs per day, and a relatively short lifespan of 2 to 3 months. The genome of Drosophila contains about 13,600 genes, $60 \%$ homologous to the human genome (Adams et al., 2000). Drosophila develop most major organs found in

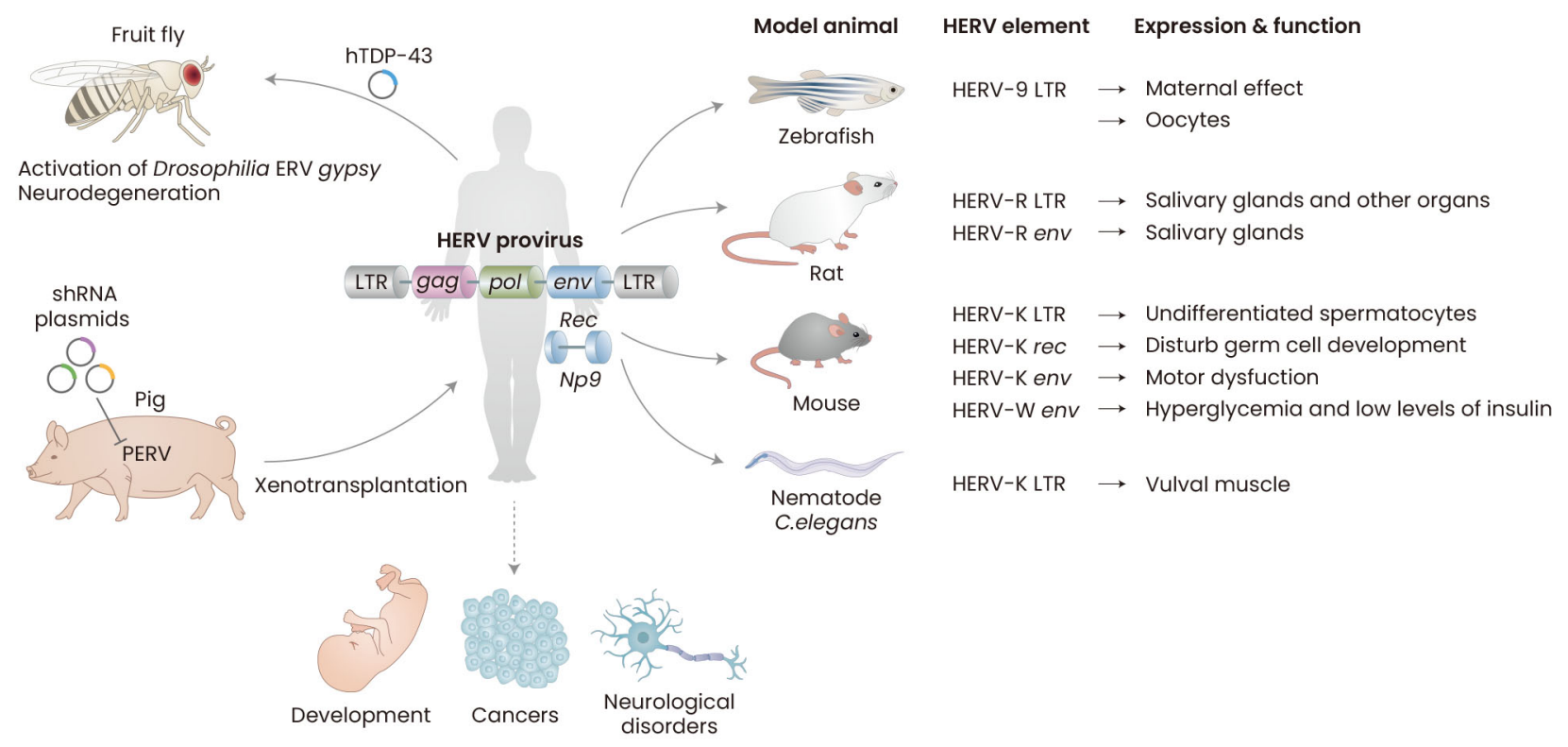

Fig. 1. Animal models used in HERV studies. HERV expression is required for normal development and its abnormal activation can result in several cancers and neurological diseases. Transgenic animals are generated by microinjection of DNA fragments or plasmids harboring HERV LTR, env, and rec genes into the pronuclei of fertilized eggs of vertebrate models of zebrafish, rats, and mice, or into the gonad of the worm C. elegans. Regulatory elements of HERV LTRs act as promoters/enhancers in many animal models and can affect the expression of the nearby gene or reporter. Some model animals expressing HERV env and rec genes show the shared features with human diseases such as cancers, ALS, and type-1 diabetes. Transgenic fruit flies expressing human TDP-43 (hTDP-43), which forms pathological aggregates in various neurodegenerative diseases such as ALS, FTD, and AD, activates Drosophila ERV gypsy, that is structurally related to HERV-K, and their neurons degenerate. Genetically modified pigs suppressing porcine endogenous retroviruses (PERVs), which are still infectious, different from HERVs, are developed to overcome a potential risk of cross-species transmission of PERVs in xenotransplantation. Tumor xenograft animal models also show that HERV elements increase cancer cell proliferation and tumor growth. Animal models can be used to analyze the role of HERV function in vivo and help better understand how they are involved in the disease process. Figure was created with BioRender.com. 
humans, including heart, hematopoietic system, and compartmented nervous system, thus serving as a useful simple model for studying circulation and behavior (Lee and Kim, 2021; Rimal et al., 2020; Vlisidou and Wood, 2015).

TAR DNA-binding protein 43 (TDP-43) is abnormally expressed in many ALS patients (Chen-Plotkin et al., 2010), and it has been reported to directly bind to HERV-K LTR (Li et al., 2015). There are five binding sites for TDP-43 in HERV-K LTRs. CHIP assay revealed that TDP-43 binds to HERV-K LTR, indicating that it may have a role as a regulator of HERV-K expression and involve in neurodegeneration. Fruit flies Drosophila expressing human TDP-43 (hTDP-43) induce retrotransposable element (RTE) expression in neurons and glia (Krug et al., 2017). hTDP-43 expression in glia causes regulatory control loss in the specific RTE, the ERV gypsy. The fly glia expressing hTDP-43 degenerate, and those transgenic flies show severely impaired locomotion. The toxicity of glial hTDP-43 is rescued by either RNAi against gypsy or pharmacologically inhibiting RTE reverse transcriptase activity by tenofovir disoproxil fumarate (TDF), zidovudine (AZT), and stavudine $(\mathrm{d} 4 \mathrm{~T})$. Altogether, the studies suggest that RTE activity may contribute to neurodegeneration in TDP-43-mediated diseases.

\section{Zebrafish}

The zebrafish Danio rerio is a freshwater fish easily cultured in regular fish tanks. A single female zebrafish lays up to 200 eggs per week (Gutiérrez-Lovera et al., 2017). The zebrafish genome contains about 26,000 protein-coding genes and shows approximately $70 \%$ of homology with the human genome, including $82 \%$ of orthologous human disease-related genes (Howe et al., 2013). The transparent model organism is particularly useful in studies directly observing ongoing events inside the live vertebrate animal body, providing detailed information in organ and neural development (Choe et al., 2020; Jung et al., 2019; 2020b; Lee et al., 2020c; Oh and Park, 2019).

Transgenic zebrafish is generated to test whether ERV-9 (also known as HERV-W) LTR drives GFP expression (Pi et al., 2004). LTR activated GFP expression in transgenic zebrafish shows a maternal effect. In the study, fluorescence level in embryos decreased 48 hours after post-fertilization, which indicates ERV-9 LTR enhancer was active during oogenesis but not active during spermatogenesis or early embryogenesis. In situ hybridizations also confirmed that ERV-9 LTR was involved in the primordial oocytes but not in spermatozoa. ERV-9 LTR was similarly active in human oocytes and stem/ progenitor cells but not active in spermatozoa and differentiated somatic cells. These results indicate that ERV-9 LTR may play a role in synthesizing maternal mRNAs required for early embryogenesis.

A zebrafish reporter line of zebrafish endogenous retrovirus (ZFERV) is recently described (Hamilton et al., 2021). Itr5, the promotor of zferv1a, is used to drive GFP expression, and ZFERV is activated in the thymus and brain. Interestingly, the expression of zferv1a is specific to T-cells, suggesting a potential role for ZFERV in lymphocyte development, immunity, and neurological diseases. ZFERV knockout is also generated by deleting LTRs of ZFERV with CRISPR/Cas9 (Yang et al.,
2018). ZFERV-deficient zebrafish embryos exhibit spinal abnormality in early embryonic development, and expression of both Delta D and Notch1 is significantly lower in zebrafish with abnormal spines than normal fish. The results suggest that ZFERV may involve in vertebral development by regulating Notch1/Delta D signaling pathway.

\section{Murine models}

Murine models such as mice and rats are widely studied mammalian models due to their small size and fast reproduction cycle of three weeks (Walsh et al., 2017). Murine ESCs are available and easily subjected for genetic manipulation; thus various humanized murine models are generated to study human diseases and health (Saito et al., 2019). Transgenic animals overexpressing HERV ENVs have been studied in multiple contexts to examine the activities of HERVs. Also, studies using murine models show that maternal effect factors affect activities of endogenous murine retroviral elements, influencing early development.

\section{HERV genes and LTRs in murine models}

HERV-R env gene expression is reported in salivary glands of transgenic rats in which the transgenes carry the complete provirus genome of ERV3 (Tanaka, 2000; Tanaka et al., 2003). The transgenic rats carrying HERV-R under the control of their own promoter also express HERV-R transcripts in the placenta, where HERV-R is highly expressed in humans. Also, immunohistochemistry results show the specific expression of ENV glycoprotein in acinar cells of the Harderian glands, but not in duct epithelial cells indicating the protein expression of HERV-R is under the control of host cell regulation. Still, the transgenic rats do not show any significant pathology.

Transgenic mice expressing the lacZ gene under the control of HERV-K LTRE3, which is active in cancer developments, are generated (Casau et al., 1999). The highest expression levels are mainly restricted to the undifferentiated spermatocytes of adult testes. HERV-K LTRE3 also drives the expression of reporters in testicular teratocarcinoma cell lines but not in other cell lines of transformed kidney cell line, breast carcinomas, an osteosarcoma, and lung and colon adenocarcinomas (Bae et al., 2020; Kim et al., 2020). The results indicate that HERV-K LTRE3 is specifically compatible with the transcriptional machinery of testes cells.

Many germ cell tumor (GCT) patients are young men, and HERV-K rec gene, a variant of the env gene, is highly expressed in GCTs (Galli et al., 2005). Transgenic mice expressing HERV-K rec gene show disturbed germ cell development and are prone to developing testicular carcinoma (Lee et al., 2019c). Transgenic mice expressing the HERV-K env gene in their neurons develop motor dysfunction, exhibiting selective loss of volume of the motor cortex, decreased synaptic activity in pyramidal neurons, dendritic spine abnormalities, and nucleolar dysfunction (Li et al., 2015). TDP-43's binding to the LTRs regulates the expression of HERV-K, which is presumably responsible for the increased expression level of HERV-K env in the postmortem brain tissue of some ALS patients.

HERV-W env has been detected in the serum, PBMCs, and pancreata of type-1 diabetes (T1D) patients. Also, there is a 
correlation between HERV-W env expression and infiltration of macrophages in the exocrine pancreas. Transgenic mice expressing HERV-W env decrease insulin level, displaying hyperglycemia and immune cell infiltration in the pancreas. The results suggest that HERV-W env may contribute to T1D pathogenesis (Levet et al., 2017).

\section{Maternal effect factors}

stella is a gene coding a protein containing an SAP-like domain and a splicing factor motif-like structure, showing maternal effect (Payer et al., 2003). stella is required for early embryonic development and found to affect maternal-to-zygotic transition (MZT) (Huang et al., 2017). stella M/ Z KO 2-cell embryos have reduced activation of the LTR-ER$V L$ family, specifically mouse endogenous retrovirus type-L (MuERV-L) elements which encode a canonical retroviral gag and pol, flanked by 5' and 3' LTR. MuERV-L knock-down in embryos by micro-injecting MuERV-L siRNA into the cytoplasm of zygotes hinders developmental progression. stella may involve in the regulation of transposable elements in 2-cell embryos and the activation of MuERV-L. The study suggests that there is a possibility that mammalian maternal effect factors may participate in early developments by regulating retroviral elements.

\section{Hybrid model of humans and mice}

Multiple sclerosis-associated retrovirus (MSRV) is a HERV-W-related retroelement and found in cell cultures isolated from patients with MS, the human inflammatory demyelinating disease (Antony et al., 2011). In order to address the pathogenicity of MSRV retroviral particles, a hybrid model of humans and mice is used (Firouzi et al., 2003). SCID model mice grafted with primary human lymphocytes obtained from healthy blood donors are humanized SCID (hu-SCID) mice. hu-SCID intraperitoneally injected with MSRV virions exhibit neurological symptoms such as partial or generalized paralysis and eventually die bleeding in the brain. Pro-inflammatory T cell cytokines such as TNF- $\alpha$ and IFN $\gamma$ are overexpressed in severely ill animals. Thus, MSRV particles have potent immune-pathogenic properties mediated by T cells.

Experimental autoimmune encephalomyelitis (EAE) is the most commonly used experimental model for MS, and it has been shown that MSRV-ENV protein, a HERV-W ENV-derived protein, can induce EAE in C57/BL6 mice when administered in emulsion together with myelin oligodendrocyte glycoprotein (MOG) peptides (Perron et al., 2013). The clinical and histopathological features of MSRV-ENV-induced disease are indistinguishable from standard EAE, supporting the HERV-W ENV protein pathogenicity in vivo.

\section{Tumor xenograft models}

Several tumor xenograft studies testing oncogenic properties of HERVs have been reported. Syncytin-1, an envelope protein encoded by the HERV W env gene, is highly expressed in human hepatocellular carcinoma (HCC) (Zhou et al., 2021). Tumor xenograft assay reveals that NIH3T3 cells overexpressing syncytin-1 induce tumor formation in nude mice. Phosphorylation of MEK1/2 and ERK1/2 and expression of syncytin-1 are upregulated in HCC, which indicates MEK/ERK pathway is likely to be crucial in syncytin-1-promoted hepatocarcinogenesis. Syncytin-1-transfected human uroepithelial cells (SV-HUC-1) also develop into UCC in xenograft nude mice, too (Yu et al., 2013).

Expression of HERV-K ENV protein is higher in various cancers, including colorectal cancer than in normal tissues (Jo et al., 2016). A tumor is not formed, or even if formed, its size is significantly reduced in nude mice injected with human DLD-1 colorectal cancer cells in which HERV-K env is knocked out using the CRISPR-Cas9 system (Ko et al., 2021a). In another study, shRNA targeting HERV-K env RNA (shRNAenv) is transfected into pancreatic cancer (PC) cells to suppress the expression of HERV-K env and then grafted into mice, which eventually show the reduced size of tumors when compared with controls (Li et al., 2017). The results indicate that HERV-K ENV protein participates in cell proliferation and tumor growth.

Acute lymphocytic leukemia cells, Raji cells, overexpressing Np9 are used for tumor xenograft in NOD-SCID mice and found to promote the growth of the xenograft leukemia cells (Chen et al., 2013). Kaposi's sarcoma-associated herpesvirus (KSHV) infection can trans-activate HERV-K, particularly the encoded oncogenic Np9 expression worsens Kaposi's sarcoma pathogenesis and KSHV-induced tumorigenesis in endothelial cells (Dai et al., 2018). Kaposi's sarcoma xenograft model, mice injected with cells, in which Np9 is stably knockdown by shRNA, significantly suppresses the tumorigenesis of Kaposi's sarcoma in vivo.

\section{Porcine models}

Pigs share many characteristics with humans such as anatomy, physiology, and metabolism, making it useful for an alternative organ donor for xenotransplantation (Gutierrez et al., 2015). PERVs are, in contrast to HERVs, still active to produce virion particles, which are infectious (Denner, 2016). Thus, there is a potential risk of cross-species transmission of porcine endogenous retroviruses (PERV), which can infect the recipient's cells. Anti-PERV shRNAs method is shown to be highly effective to knock-down the expression of pol and gag genes of PERVs in pigs (Ramsoondar et al., 2009).

\section{TRANSCRIPTION FACTORS BINDING HERV LTRS}

The association between LTR sequence and cell line-specific expression suggests that certain sequence-specific elements, such as TFBSs, play a pivotal role in determining differential promoter activity. Identification of TFBSs and of their actual interactors is essential to assess the promoter activity of HERV LTRs, which drives gene expression in various situations, including human diseases (Montesion et al., 2018) (Table 1).

Double Homeobox 4 (DUX4) is a transcription factor, and its misexpression in skeletal muscle results in facioscapulohumeral muscular dystrophy (FSHD), an inherited muscle disease. DUX4 binds to the LTRs of HERV-L in rhabdomyosarcoma (RD) cells (Mitsuhashi et al., 2021), while it binds to those of HERV-K in myoblast cell lines (Young et al., 2013). DUX4 induces several HERV fusion transcripts and might significantly contribute to the pathology of FSHD.

SLE is an autoimmune disease and the most common type 


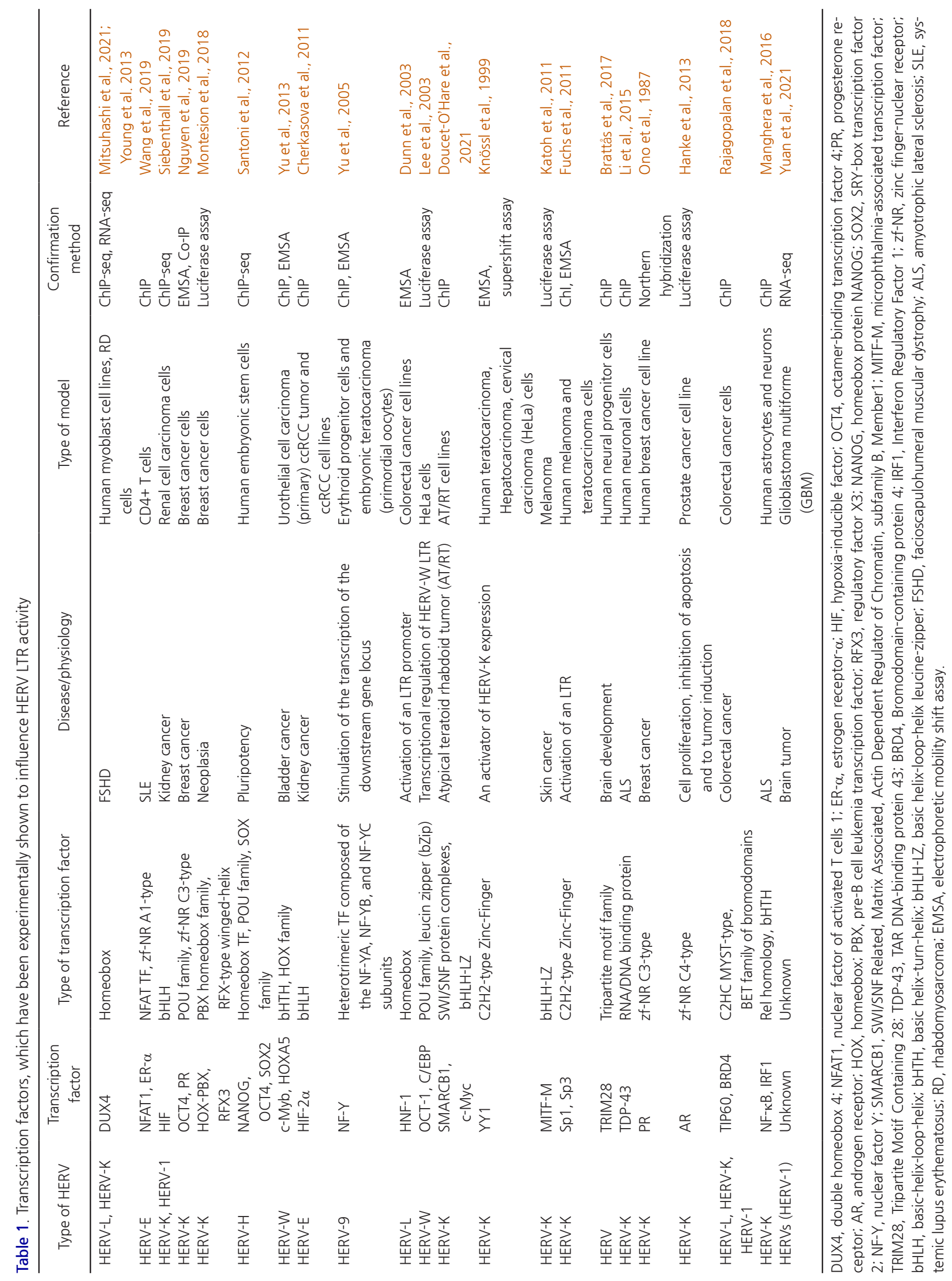


of lupus, and it is reported that high level of HERV-E clone 4-1 mRNAs are detected in CD4 ${ }^{+} T$ cells from SLE patients (Wang et al., 2019). Both nuclear factors of activated T cells 1 (NFAT1) and estrogen receptor $-\alpha(E R-\alpha)$ bind to HERV-E clone 4-1 5'LTRs where DNAs are hypomethylated. Therefore, HERV-E in CD4 ${ }^{+} \mathrm{T}$ cells can be activated by abnormal inflammatory responses in SLE.

Hypoxia-inducible transcription factor- $2 \alpha$ (HIF-2 $\alpha$ ) binds to HIF response elements (HRE) localized in proviral LTRs of HERV-E in the clear cell histological subtype of renal cell carcinoma (ccRCC) and activates HERV-E expression (Cherkasova et al., 2011). The expression of a novel transcript derived from HERV-E provirus named CT-RCC HERV-E is restricted to $C C R C C$, which is characterized by inactivation of the von Hippel-Lindau (VHL) tumor-suppressor gene. Transfection of a cCRCC tumor line with a plasmid expressing functional VHL significantly reduces the expression of CT-RCC HERV-E transcripts. The results suggest that inactivation of tumor suppressor VHL may be associated with HERV-E expression in cCRCC.

HIFs, HIF- $1 \alpha, H I F-2 \alpha$, and HIF- $1 \beta$, are all reported to bind to the LTRs of class I HERVs and HERV-K families, and HIFbound LTRs show a promoter-like activity driving expression of POU5F1 (OCT4), a stem cell transcription factor, in RCCs (Moon et al., 2020; Siebenthall et al., 2019). POU5F1 is consistently upregulated in tumor cells in Cancer Genome Atlas (TCGA) cohorts. Progesterone receptor (PR) and OCT4 bind progesterone-response element (PRE) and an octamer motif, respectively, in a long terminal repeat LTR5HS of HERV-K, activating transcription downstream of the LTR5HS in human breast cancer cells T47D, in which the activation of HERVKs by female hormones have been reported (Nguyen et al., 2019; Ono et al., 1987).

A specific mutation in HERV-W LTRs is significantly associated with the pathology of UCC and with syncytin-1 overexpression. c-Myb binds to 3'-LTRs of HERV-W, which depends on 142T > C mutation (Yu et al., 2013). The mutant 3'-LTR acts as an enhancer for syncytin-1 gene expression, stimulated by c-Myb in UCC. The results indicate that the HERV-W 3 '-LTRs can be a regulatory element affecting syncytin-1 gene expression, participating in tumor development. On the other hand, HOXA5 is shown to bind normal HERV-W 3'-LTR, also regulating syncytin-1 gene expression.

In colorectal cancer cells, hepatocyte nuclear factor 1 (HNF1) binds to the LTR of HERV-L, which acts as an alternative promoter for the human $\beta 1$,3-galactosyltransferase 5 gene (Dunn et al., 2003). It is found that the HERV-L LTR is a dominant promoter in the colon and has a significant impact on the gene expression of $\beta 3 \mathrm{Gal}-\mathrm{T5}$.

HERV-K expression is upregulated in neural tissues from ALS patients. Independent and synergistic upregulation of HERV-K by interferon regulatory factor 1 (IRF1), NF- ${ }^{-K B}$ isoforms $\mathrm{p} 50$ and $\mathrm{p} 65$ are observed in ALS patients' astrocytes and neurons (Manghera et al., 2016). Treatment with cytokines TNF- $\alpha$ and LIGHT (the lymphotoxin-like inducible protein that competes with glycoprotein $D$ for herpes virus entry on T cells) increase the levels of HERV-K transcript and protein through the direct interaction between both interferon regulatory factor 1 (IRF1) and NF- ${ }_{\kappa} \mathrm{B}$ and the interferon-stimulated response elements (ISREs) located in the HERV-K LTRs. Cytokine-mediated IRF1 and $\mathrm{NF}^{-} \mathrm{KB}$ binding to the HERV-K LTR is in a cell-type-dependent manner. TNF- $\alpha$ increases HERV-K protein levels in neurons, whereas LIGHT induces HERV-K in astrocytes.

Several transcriptional initiator (Inr) sites in the HERV-K LTRs are detected by rapid amplification of complementary DNA ends (5' RACE) (Katoh et al., 2011). The most potent Inr is associated with a TATA box and three binding motifs of microphthalmia-associated transcription factor (MITF). Both chromosomal HERV-K and the cloned LTRs are strongly activated in HEK293, which are transfected with MITF-M, a melanocyte/melanoma-specific isoform of MITF. In malignant melanoma lines, HERV-K transcription is enhanced when compared with normal melanocytes.

Gel shift assay shows that binding complexes, which are formed on the enhancer sequence by protein extracts of HERV-K-expressing teratocarcinoma cell lines $\mathrm{GH}$ and Tera2 form, are different from those of HeLa and HepG2 cells, both of which do not express HERV-K (Knössl et al., 1999). Combined results obtained from competition gel shift assay, DNase I footprinting, and supershift experiments indicate that the binding site of these complexes is a 20-bp sequence within HERV-K enhancer, and the transcription factor $Y Y 1$ was one component of the HERV-K enhancer-bound complex.

Transcription factors Sp1 and Sp3 also interact with HERV-K LTRs (Fuchs et al., 2011). Both mutating specific GC boxes, which are binding sites for Sp proteins, and knocking down Sp1 and Sp3 with small interfering RNA (siRNA) significantly interfere with the promoter activity of HERV-K LTRs in human melanoma and teratocarcinoma cells.

Gliomas originated from astrocytes, oligodendrocytes, and ependymal cells attributes more than $70 \%$ of all brain tumors (Ohgaki and Kleihues, 2005). Glioblastoma multiforme (GBM) arises from the uncontrolled proliferation of astrocytes and is one of the most aggressive types of malignant brain tumors (Buckner et al., 2007; Kim et al., 2021; Ostrom et al., 2015). The analyses of the various genome and transcriptome data sets generated from GBM tissues and normal brain tissues identify some differentially expressed repetitive elements (Jung et al., 2020a; Yuan et al., 2021). Forty-eight of those repetitive elements are LTR elements, of which 46 are derived from HERV elements. Forty-three out of the 46 differentially expressed HERV elements are upregulated, and 34 significantly changed HERV elements belong to the class I superfamily. The LTR elements from HERVs are potential biomarkers for immunotherapy to treat GBM. Expression levels of these elements could be monitored as biomarkers to treat GBM.

The Rec protein of HERV-K interacts with human small glutamine-rich tetratricopeptide repeat (TPR)-containing protein (hSGT) which is a cellular androgen receptor (AR) inhibitor (Hanke et al., 2013). This interaction was confirmed by co-immunoprecipitation, pull-down assays, and colocalization experiments. Rec interference with hSGT induces AR activity. Rec also acts as a transactivator by enhancing AR-mediated activation of the HERV-K LTR promoter. Rec-driven hyperactivation of the AR leads to increased cell proliferation and 
inhibition of apoptosis and eventually to tumor induction or promotion.

An atypical teratoid rhabdoid tumor (AT/RT) is an embryonal central nervous system (CNS) cancer often characterized by loss of SMARCB1 (SWI/SNF Related, Matrix Associated, Actin Dependent Regulator of Chromatin, subfamily B, Member 1). SMARCB1 is a tumor suppressor gene and essential during development. AT/RTs contain undifferentiated cancer cells (Nemes and Frühwald, 2018). The repression of HERV-K env retains stem cell features and enhances neuronal differentiation (Wang et al., 2020a). In AT/RT cell lines, loss of SMARCB1 in neural stem cells (NSCS) results in upregulation of HERV-K env, but restoration of SMARCB1 leads to downregulation of HERV-K env (Doucet-O'Hare et al., 2021). In the absence of SMARCB1, c-Myc binds to HERV-K LTR and increases HERV-K expression. However, SMARCB1 interferes with $\mathrm{c}-\mathrm{Myc}$, binds to HERV-K LTR, and represses HERV-K expression, when overexpressed. HERV-K activation in the development of undifferentiated tumors in AT/RT suggests it may play a critical role in human embryonic and neurodevelopment.

\section{MOLECULAR AND CELLULAR EVENTS CONTROLLED BY HERV ELEMENTS}

HERV elements actively control multiple molecular and cellular events in different cells including neurons, glia, cancer and stem cells in various physiological and pathological conditions (Table 2).

\section{Toll-like receptor (TLR) signaling: TLR-3 and TLR-4}

Elevated levels of TLR-3 and IL-6 are detected in syncytin-1-overexpressing human microglia cell line CHME-5 and astrocyte cell line U251 (Wang et al., 2018). The syncy-

Table 2. Roles of HERV elements in signaling pathways

\begin{tabular}{|c|c|c|c|}
\hline $\begin{array}{l}\text { HERV } \\
\text { elements }\end{array}$ & Signaling pathways & Effects & Reference \\
\hline MSRV-Env & TLR4 pathway & $\begin{array}{l}\text { - Acts as agonist of human TLR-4 } \\
\text { - Impairs human OPC maturation to myelinating oligodendrocytes } \\
\text { - Induces TLR4-dependent pro-inflammatory stimulation of immune } \\
\text { cells } \\
\text { - Induces over-expression of ICAM-1 and stimulates inflammatory } \\
\text { factors in BBB in vitro model }\end{array}$ & $\begin{array}{l}\text { Madeira et al., } \\
2016 \\
\text { Duperray et al., } \\
2015\end{array}$ \\
\hline MSRV-Env-SU & CD14 and TLR-4 pathway & $\begin{array}{l}\text { - Triggers maturation process in human dendritic cells } \\
\text { - Induces human monocytes to produce major proinflammatory cy- } \\
\text { tokines through CD14 and TLR4 }\end{array}$ & $\begin{array}{l}\text { Rolland et al., } \\
2006\end{array}$ \\
\hline \multirow[t]{4}{*}{ HERV-W-env } & TLR4/MyD88 pathway & $\begin{array}{l}\text { - Upregulates the expressions of inflammatory cytokines through } \\
\text { TLR4/MyD88 pathway in glial cells }\end{array}$ & Wang et al., 2021 \\
\hline & BDNF signaling & $\begin{array}{l}\text { - Increases the expression of BDNF, NTRK2, and DRD3 that contribute } \\
\text { to the pathogenesis of the schizophrenia }\end{array}$ & Huang et al., 2011 \\
\hline & TRPC3 channel & - Induces Ca2+ influx through TRP3 channel and regulates DISC1 & Chen et al., 2019 \\
\hline & SK3 channel & - Induces SK3 dependent on CRE/CREB in human neuroblastoma cells & Li et al., 2013 \\
\hline \multirow[t]{3}{*}{ Syncytin-1 } & MEK/ERK pathway & $\begin{array}{l}\text { - Promotes cell proliferation, metastasis, and tumorigenicity in hu- } \\
\text { man hepatocellular carcinoma (HCC) }\end{array}$ & Zhou et al., 2021 \\
\hline & TLR3 pathway & $\begin{array}{l}\text { - Activates TLR-3 signaling and induces the production of CRP in mi- } \\
\text { croglia and astrocytes }\end{array}$ & Wang et al., 2018 \\
\hline & TGF- $\beta$ signaling & - Proliferation and cell-cell fusions & Strick et al., 2007 \\
\hline \multirow[t]{3}{*}{ HERV-K env } & Ras signaling & - Promotes tumorigenesis in breast cancer (BC) & Zhou et al., 2016 \\
\hline & $\begin{array}{l}\text { ROS-NUPR } 1 \text { pathway } \\
\text { mTOR pathway }\end{array}$ & $\begin{array}{l}\text { - Tumor proliferation, invasion, migration in colorectal cancer } \\
\text { - Interacts with CD98HC, triggers mTOR and regulates of stem cell } \\
\text { function/neuronal differentiation }\end{array}$ & $\begin{array}{l}\text { Ko et al., } 2021 \text { a } \\
\text { Wang et al., } \\
2020 b\end{array}$ \\
\hline & ERK1/2 pathway & - Induces epithelial to mesenchymal transition (EMT) & $\begin{array}{l}\text { Lemaître et al., } \\
2017\end{array}$ \\
\hline HERV-K LTR & NTRK3 signaling pathway & - Induces NTRK3 expression and impairs cortical neuron development & $\begin{array}{l}\text { Padmanabhan } \\
\text { Nair et al., } 2021\end{array}$ \\
\hline $\begin{array}{l}\text { HERV-K gag } \\
\text { and env }\end{array}$ & $\begin{array}{l}\text { MEK-ERK and p16INK4A- } \\
\text { CDK4 pathways }\end{array}$ & $\begin{array}{l}\text { - Potential regulator of BRAF-MEK-ERK and p16INK4A-CDK4-RB } \\
\text { during melanoma pathogenesis }\end{array}$ & Li et al., 2010 \\
\hline HERV-K Np9 & $\begin{array}{l}\beta \text {-catenin, ERK, Akt and } \\
\text { Notch1 signaling }\end{array}$ & $\begin{array}{l}\text { - Activates } \beta \text {-catenin, ERK, Akt and Notch1 signaling pathways and } \\
\text { regulates the growth of human leukemia stem/progenitor cells }\end{array}$ & Chen et al., 2013 \\
\hline
\end{tabular}

MSRV-Env, multiple sclerosis associated retrovirus envelope protein, member of the W family of HERV (HERV-W); MSRV-Env-SU, the surface unit of the MSRV envelope protein; OPC, oligodendrocyte precursors cells; PBMC, peripheral blood mononuclear cells; BBB, blood-brain barrier; ICAM-1, intercellular adhesion molecule 1; BDNF, brain-derived neurotrophic factor; DISC1, disrupted-in-schizophrenia 1; CREB, CAMP response element-binding protein; CRE, CAMP response element; CD98HC, a heterodimeric amino acid transporter; NTRK3, neurotrophic tyrosine receptor kinase 3. 
tin-1-induced mRNA levels of C-reactive protein (CRP) are decreased in both cell lines that are knocked down of TLR3. The reduced gene expression of TLR-3 also decreases the phosphorylation of IRF3 that is a downstream signaling molecule of TLR-3. These results suggest that syncytin-1 participates in inflammatory regulation in glial cells via the TLR3 signaling pathway.

ENV protein of MSRV that is the MS-related HERV-W acts as a potent agonist to TLR-4, a pattern recognition receptor of innate immunity, and induces inflammation, increasing the release of interleukin- 6 (IL- 6$)$ and TNF- $\alpha$ cytokines from human peripheral blood mononuclear cells (hPBMC) (Ahmed et al., 2020; Madeira et al., 2016). These effects of MSRV-ENV are inhibited by GNbAC1, a humanized monoclonal antibody targeting MSRV-ENV, which may be helpful in the treatment of MS. The pro-inflammatory property of MSRV-ENV is also demonstrated in murine models. Intravenously injected MSRV-ENV induces a strong release of IL- 6 and TNF- $\alpha$, and administration and GNbAC1 block it. In addition, MSRV-ENV suppresses differentiation of human oligodendrocyte precursor cells (hOPC) through TLR-4, and impairs demyelination that is a hallmark of MS. MSRV-ENV also exerts its pro-inflammatory activity on the blood-brain barrier (BBB) (Duperray et al., 2015). MSRV-ENV induces overexpression of ICAM-1, a significant mediator adhesion between activated immune cells and endothelial cells, and production of the pro-inflammatory cytokines IL-6 and IL-8 in HCMEC/D3 brain endothelial cell line, on which TLR-4 is expressed (Rolland et al., 2006). MSRV-ENV activates human monocytes, inducing the secretion of IL- 6 , TNF- $\alpha$, and IL- $1 \beta$ from monocytes, and those activities are dependent on TLR- 4 and CD14 receptors. These receptors are also involved in MSRV-ENV-mediated activation of dendritic cells (DC) and promote the development of Th1-like responses.

Syncytin-1, the HERV-W ENV protein ERVWE1, is also found highly expressed in the serums of schizophrenic patients (Perron et al., 2008). Neuroinflammation contributes to neuropsychiatric disorders such as schizophrenia, and HERV-W ENV is involved in producing the inflammation-related cytokines. In human glioma cell lines U251 and A172, overexpression of HERV-W ENV lead to an increase in mRNA levels of TNF- $\alpha$ and IL-10 and the mRNA levels of TLR-4, which mediates the production of pro-inflammatory cytokines (Romao et al., 2012). Myeloid differentiation primary response 88 (MyD88) is downstream of TLR-4, and overexpressed HERV-W ENV also increases the mRNA levels of MyD88 (Kuzmich et al., 2017). Knock-down of TLR- 4 decreases the release of TNF- $\alpha$ and IL-10 induced by HERV-W ENV, suggesting that HERV-W involvement in neuroinflammation depends on TLR4/MyD88 signaling pathway in glial cells (Wang et al., 2021). Together with syncytin-1, CRP, an acute inflammatory marker, is also detected at high levels in the serum of schizophrenia patients (Misiak et al., 2018). mRNA and protein levels of CRP increase in CHME-5 and U251 cells overexpressing syncytin-1 (Wang et al., 2018). Moreover, syncytin-1 promotes the activity of CRP promoters, playing a regulatory role in CRP expression.

\section{Syncytin-1 changes cellular signaling in neurons and glia}

Overexpression of syncytin-1 upregulates brain-derived neurotrophic factor (BDNF), neurotrophic tyrosine kinase receptor type 2 (NTRK2), and dopamine receptor D3, and phosphorylation of CAMP (cyclic adenosine monophosphate) response element-binding (CREB) protein in human glioma cells (Huang et al., 2011). Syncytin-1 interacts with BDNF promoter, enhancing transcription. In human neuroblastoma cells, syncytin-1 activates the promoter of small conductance $\mathrm{Ca}^{2+}$-activated $\mathrm{K}^{+}$channel protein 3 (SK3), depending on both CREB and CAMP response element (CRE) (Li et al., 2013). In neuroblastoma cells, syncytin-1 overexpression induces $\mathrm{Ca}^{2+}$ influx through transient receptor potential cation channel subfamily C member 3 (TRPC3) channels by directly regulating its expression or by downregulating the gene disrupted-in-schizophrenia 1 (DISC1) (Chen et al., 2019; Dhakal and Lee, 2019). These conditions contribute to the pathogenesis of schizophrenia; thus, HERV-W may also involve in the development of psychotic disorders.

\section{HERV coding proteins affect signaling pathways in can- cers}

Syncytin-1 promotes cell proliferation, metastasis, and tumorigenicity in HCC by activating MEK/ERK pathway. It is shown that syncytin-1 upregulates MEK/ERK downstream proteins such as c-Myc, c-Fos, c-Jun, CCND1, and CDK4 in HCC (Zhou et al., 2021). HERV-K ENV induces epithelial to mesenchymal transition (EMT), which promotes cell motility in human breast epithelial cells, activating the ERK1/2 pathway (Lee et al., 2019a; Lemaître et al., 2017). The downstream events include increased expression of various transcription factors such as EGR1, ZCCHC12, ETV4, and ETV5, which are tightly related to oncogenesis. HERV-K ENV is also reported to increase Ras-induced ERK activation in human breast cancer cells and promote tumorigenesis (Wang et al., 2020c; Zhou et al., 2016). These findings lead to a therapeutic approach using anti-HERV-K ENV, which is potential for immunotherapy of breast cancer. A chimeric antigen receptor (CAR) specific for HERV-K ENV protein (K-CAR) has an anti-metastatic activity, inhibiting cell proliferation in vitro and tumorigenesis in vivo (Zhou et al., 2015). A recent study shows that CRISPR-Cas9 mediated knock-down of the HERV-K ENV gene in DLD-1 colorectal cancer showed reduced proliferation, invasion, migration, and tumor colonization by activating the ROS-NUPR1 pathway (Ko et al., 2021b).

Syncytin-1 expression is significantly increased in endometrial carcinomas (EnCa) (Strick et al., 2007). Treatment with steroid hormone estrogen induces syncytin-1 expression in primary EnCa cells and increases cell proliferation. DNA binding assays reveal that ER binds explicitly to the syncytin-1 ERE, an estrogen response element located in the LTR of HERV-W. Therefore, steroid hormones directly regulate syncytin-1 gene expression. In addition, syncytin-1 is also upregulated in EnCa cells treated with the SP isomer of CAMP (SP-CAMP), and those EnCa cells undergo proliferation and cell-cell fusion, which are blocked by silencing of syncytin-1 gene expression. The addition of purified TGF- $\beta 1$ or TGF- $\beta 3$ proteins to SPCAMP treated EnCa cells inhibits cell-cell fusion while the high level of syncytin-1 is unchanged. The result indicates that TGF- $\beta$ treatment can revoke syncytin-1-mediated cell-cell fusions, which may provide a therapeutic option in endome- 
trial cancers.

Both HERV-K GAG and ENV are highly expressed in melanoma cells, in which phosphorylation of ERK is also increased. In contrast, p16INK4a suppresses tumors by inhibiting cyclin-dependent kinases CDK4 and CDK6 (Quelle et al., 1995) and is detected in mostly nevus cells rather than melanoma cells (Li et al., 2010). These studies show a positive correlation between the levels of HERV-K GAG and ENV proteins with activation of MEK/ERK pathway and loss of p16INK4A-CDK4 activities in melanoma cells.

Overexpression of HERV-K type 1-encoded Np9 induces the growth of leukemia cells, whereas knock-down of Np9 expression inhibits the growth of myeloid and lymphoblastic leukemia cells (Chen et al., 2013). These results indicate that Np9 is essential for the survival and growth of myeloid and lymphoblastic leukemia cells. Overexpression of Np9 is also reported to increase the protein levels of $\beta$-catenin, ERK, Akt, and Notch 1 signaling molecules, whereas silencing of Np9 causes a significant decrease of expression levels of c-Myc, pERK1, phospho-Akt (pAkt), and cleaved Notch1 in leukemia cells.

\section{ENVs in stem cells}

HERV-K ENV is reported to be expressed in the cell membrane of pluripotent stem cells and interact with a heterodimeric amino acid transporter CD98HC (Wang et al., 2020b). The interaction leads to triggering mammalian targets of rapamycin (mTOR) and lysophosphatidylcholine acyltransferase (LPCAT1) pathways that regulate stem cell function. Down-regulation of HERV-K ENV was shown to promote neuronal differentiation of stem cells.

LTR promoter of HERV-K is activated in hESCs by the CRISPR activation (CRISPRa) method (Padmanabhan Nair et al., 2021). HERV-K activated hESCs are differentiated into cortical neurons. Those cortical neurons display a drastic reduction in microtubule-associated protein 2 (MAP2) expression, which is a neuron-specific cytoskeletal protein and a marker for neuronal cells (Dinsmore and Solomon, 1991). These cortical neurons exhibit shorter axons with fewer branches. Activated HERV-K LTR also robustly upregulates neurotrophic tyrosine receptor kinase 3 (NTRK3), critical in cortical neuron development (Bartkowska et al., 2007). The knock-down of NTRK3 in HERV-K LTR-activated cortical neurons reverts the observed phenotypes, suggesting that HERV-K activation impairs NTRK3-dependent cortical neuron development, which ultimately results in abnormal brain development (Padmanabhan Nair et al., 2021).

\section{HERVs in COVID-19}

Recently, several studies report that HERVs are activated in COVID-19 infection. IFN-1, IFN-2, TRIM28, SETDB1, and viral genes of HERV-H, $-\mathrm{K}$, and $-\mathrm{W}$ families are upregulated in peripheral blood from children between 4-8 years suffering from COVID-19 with mild symptoms, whereas downregulated in severe cases (Tovo et al., 2021). The correlative expression of these genes according to the severity of COVID-19 suggests that there are distinct phases of the disease, for which the differentially regulated genes may serve as prognostic markers. The syncytin-1 protein level is high in blood samples from adult COVID-19 patients (Balestrieri et al., 2021; Garcia-Montojo and Nath, 2021). The expression of syncytin-1 is also correlated with the markers of T-cell differentiation such as IL-6, IL-10, IL-17, IL-17RA, MCP1, and CXCR1. Syncytin-1-positive lymphocytes and inflammatory markers are correlated with the severity of pneumonia in COVID-19 patients.

A recombinant baculovirus expressing the envelope of HERV-W (AcHERV) is constructed as a DNA vaccine system against Middle East respiratory syndrome coronavirus (MERSCoV) and the severe acute respiratory syndrome coronavirus-2 (SARS-CoV2), responsible for COVID-19 (Cho et al., 2021; Shah and Woo, 2021). Baculoviruses possess a nuclear transport signal which enables an efficient gene expression of inserted full-length S, S1 subunit, or RBD antigens of MERSCOV or SARS-CoV2 with multiple boosting. The ACHERVCOVID19-S vaccine induces serum IgG, neutralizing antibody, and antigen-specific IFN- $\gamma$ secretion, indicating high cellular immunity. AcHERV-MERS-S1 also prompts high levels of IgG, neutralizing antibody, and T-cell immune responses. AcHERV-DNA vaccines provide increased protection against MERS-CoV and SARS-CoV2 in animal models, supporting the feasibility of ACHERV-MERS or AcHERV-COVID19 vaccines in preventing pandemic spreads of viral infections.

\section{CONCLUSION}

HERVs are ancient sequences of exogenous retroviruses integrated into the human genome and are considered viral "fossils". Although most HERVs have accumulated mutations and lost their coding capability, they still retain some activities in terms of HERV-mediated regulation of host gene expression. Many studies have revealed that abnormal activation and expression of HERV genes can lead to severe illnesses like cancers, autoimmune diseases, and neurological diseases. Various endogenous transcription factors regulating cell proliferation and differentiation bind to specific motifs in HERV LTRs, which act as a promoter or an enhancer. Downstream events include activation of various signaling pathways such as TLR-4 and MEK/ERK. While a number of stimulators are known to activate HERV genes inadequately, the recent report shows that expression patterns of HERV genes fluctuate in the progress of COVID-19. The more profound insight into the mechanisms explaining the roles HERV activities in various biological contexts will help develop clinical applications targeting HERVs and set up diagnostic and prognostic biomarkers for related diseases, even unprecedented pandemic illness of COVID-19.

Note: Supplementary information is available on the Molecules and Cells website (www.molcells.org).

\section{ACKNOWLEDGMENTS}

This research was supported by the Basic Science Research Program through the National Research Foundation of Korea (NRF) funded by the Ministry of Education, Science and Technology (2021R1F1A1049211) and by Institute of Information \& Communications Technology Planning \& Evaluation (IITP) grant funded by the Korea government (MSIT) (No. 2020-0- 
01373, Artificial Intelligence Graduate School Program [Hanyang University]). We sincerely apologize to our colleagues in case we unwittingly omit their valuable works in this review.

\section{AUTHOR CONTRIBUTIONS}

S.D., S.K.L., and J.A. conceived research and wrote the manuscript. S.K.L. and J.A. secured funding.

\section{CONFLICT OF INTEREST}

The authors have no potential conflicts of interest to disclose.

\section{ORCID}

Serpen Durnaoglu https://orcid.org/0000-0001-6902-2492

Sun-Kyung Lee https://orcid.org/0000-0001-5368-0722

Joohong Ahnn https://orcid.org/0000-0003-2229-3580

\section{REFERENCES}

Adams, M.D., Celniker, S.E., Holt, R.A., Evans, C.A., Gocayne, J.D. Amanatides, P.G., Scherer, S.E., Li, P.W., Hoskins, R.A., Galle, R.F., et al. (2000). The genome sequence of Drosophila melanogaster. Science 287, 2185-2195.

Ahmed, M.B., Islam, S.U., and Lee, Y.S. (2020). Decursin negatively regulates LPS-induced upregulation of the TLR4 and JNK signaling stimulated by the expression of PRP4 in vitro. Anim. Cells Syst. (Seoul) 24, 44-52.

Alqahtani, S., Promtong, P., Oliver, A.W., He, X.T., Walker, T.D., Povey, A., Hampson, L., and Hampson, I.N. (2016). Silver nanoparticles exhibit sizedependent differential toxicity and induce expression of syncytin-1 in FAAML1 and MOLT-4 leukaemia cell lines. Mutagenesis 31, 695-702.

Anand, D., Colpo, G.D., Zeni, G., Zeni, C.P., and Teixeira, A.L. (2017). Attention-deficit/hyperactivity disorder and inflammation: what does current knowledge tell us? A systematic review. Front. Psychiatry 8, 228.

Antony, J.M., DesLauriers, A.M., Bhat, R.K., Ellestad, K.K., and Power, C. (2011). Human endogenous retroviruses and multiple sclerosis: innocent bystanders or disease determinants? Biochim. Biophys. Acta 1812, 162176.

Attig, J., Young, G.R., Hosie, L., Perkins, D., Encheva-Yokoya, V., Stoye, J.P., Snijders, A.P., Ternette, N., and Kassiotis, G. (2019). LTR retroelement expansion of the human cancer transcriptome and immunopeptidome revealed by de novo transcript assembly. Genome Res. 29, 1578-1590.

Bae, S., Kim, M.K., Kim, H.S., and Moon, Y.A. (2020). Arachidonic acid induces ER stress and apoptosis in HT-29 human colon cancer cells. Anim. Cells Syst. (Seoul) 24, 260-266.

Balada, E., Ordi-Ros, J., and Vilardell-Tarrés, M. (2009). Molecular mechanisms mediated by human endogenous retroviruses (HERVs) in autoimmunity. Rev. Med. Virol. 19, 273-286.

Balestrieri, E., Arpino, C., Matteucci, C., Sorrentino, R., Pica, F., Alessandrelli, R., Coniglio, A., Curatolo, P., Rezza, G., Macciardi, F., et al. (2012). HERVs expression in autism spectrum disorders. Plos One 7, e48831.

Balestrieri, E., Cipriani, C., Matteucci, C., Benvenuto, A., Coniglio, A., ArgawDenboba, A., Toschi, N., Bucci, I., Miele, M.T., Grelli, S., et al. (2019). Children with autism spectrum disorder and their mothers share abnormal expression of selected endogenous retroviruses families and cytokines. Front. Immunol. 10, 2244.

Balestrieri, E., Minutolo, A., Petrone, V., Fanelli, M., lannetta, M., Malagnino, V., Zordan, M., Vitale, P., Charvet, B., Horvat, B., et al. (2021). Evidence of the pathogenic HERV-W envelope expression in T lymphocytes in association with the respiratory outcome of COVID-19 patients. EBioMedicine 66, 103341.
Bannert, N. and Kurth, R. (2004). Retroelements and the human genome: new perspectives on an old relation. Proc. Natl. Acad. Sci. U. S. A. 101 (Suppl 2), 14572-14579.

Bartkowska, K., Paquin, A., Gauthier, A.S., Kaplan, D.R., and Miller, F.D. (2007). Trk signaling regulates neural precursor cell proliferation and differentiation during cortical development. Development 134, 43694380.

Bergallo, M., Galliano, I., Daprà, V., Pirra, A., Montanari, P., Pavan, M., Calvi, C., Bertino, E., Coscia, A., and Tovo, P.A. (2019). Transcriptional activity of human endogenous retroviruses in response to prenatal exposure of maternal cigarette smoking. Am. J. Perinatol. 36, 1060-1065.

Bergallo, M., Galliano, I., Montanari, P., Gambarino, S., Mareschi, K., Ferro, F., Fagioli, F., Tovo, P.A., and Ravanini, P. (2015). CMV induces HERV-K and HERV-W expression in kidney transplant recipients. J. Clin. Virol. 68, 28-31.

Blomberg, J., Nived, O., Pipkorn, R., Bengtsson, A., Erlinge, D., and Sturfelt, G. (1994). Increased antiretroviral antibody reactivity in sera from a defined population of patients with systemic lupus erythematosus. Arthritis Rheum. 37, 57-66.

Brattås, P.L., Jönsson, M.E., Fasching, L., Nelander Wahlestedt, J., Shahsavani, M., Falk, R., Falk, A., Jern, P., Parmar, M., and Jakobsson, J. (2017). TRIM28 controls a gene regulatory network based on endogenous retroviruses in human neural progenitor cells. Cell Rep. 18, 1-11.

Brodziak, A., Ziółko, E., Muc-Wierzgoń, M., Nowakowska-Zajdel, E., Kokot, T., and Klakla, K. (2012). The role of human endogenous retroviruses in the pathogenesis of autoimmune diseases. Med. Sci. Monit. 18, RA80RA88.

Buckner, J.C., Brown, P.D., O'Neill, B.P., Meyer, F.B., Wetmore, C.J., and Uhm, J.H. (2007). Central nervous system tumors. Mayo Clin. Proc. 82, 1271-1286.

Burns, K.H. (2017). Transposable elements in cancer. Nat. Rev. Cancer 17, 415-424.

C. elegans Sequencing Consortium (1998). Genome sequence of the nematode C. elegans: a platform for investigating biology. Science 282, 2012-2018.

Casau, A.E., Vaughan, J.E., Lozano, G., and Levine, A.J. (1999). Germ cell expression of an isolated human endogenous retroviral long terminal repeat of the HERV-K/HTDV family in transgenic mice. J. Virol. 73, 99769983.

Chan, S.M., Sapir, T., Park, S.S., Rual, J.F., Contreras-Galindo, R., Reiner, O., and Markovitz, D.M. (2019). The HERV-K accessory protein Np9 controls viability and migration of teratocarcinoma cells. Plos One 14, e0212970.

Chen-Plotkin, A.S., Lee, V.M.Y., and Trojanowski, J.Q. (2010). TAR DNAbinding protein 43 in neurodegenerative disease. Nat. Rev. Neurol. 6, 211220

Chen, T., Meng, Z., Gan, Y., Wang, X., Xu, F., Gu, Y., Xu, X., Tang, J., Zhou, H.,

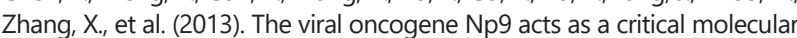
switch for co-activating $\beta$-catenin, ERK, Akt and Notch1 and promoting the growth of human leukemia stem/progenitor cells. Leukemia 27, 14691478.

Chen, Y., Yan, Q., Zhou, P., Li, S., and Zhu, F. (2019). HERV-W env regulates calcium influx via activating TRPC3 channel together with depressing DISC1 in human neuroblastoma cells. J. Neurovirol. 25, 101-113.

Cherkasova, E., Malinzak, E., Rao, S., Takahashi, Y., Senchenko, V.N., Kudryavtseva, A.V., Nickerson, M.L., Merino, M., Hong, J.A., Schrump, D.S. et al. (2011). Inactivation of the von Hippel-Lindau tumor suppressor leads to selective expression of a human endogenous retrovirus in kidney cancer. Oncogene 30, 4697-4706.

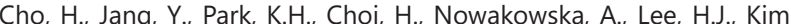
M., Kang, M.H., Kim, J.H., Shin, H.Y., et al. (2021). Human endogenous retrovirus-enveloped baculoviral DNA vaccines against MERS-CoV and SARS-CoV2. NPJ Vaccines 6, 37. 
Choe, S., Huh, T.L., and Rhee, M. (2020). Trim45 is essential to the development of the diencephalon and eye in zebrafish embryos. Anim. Cells Syst. (Seoul) 24, 99-106.

Chung, K.W., Kim, J.S., and Lee, K.S. (2020). A database of Caenorhabditis elegans locomotion and body posture phenotypes for the peripheral neuropathy model. Mol. Cells 43, 880-888.

Chuong, E.B., Elde, N.C., and Feschotte, C. (2016). Regulatory evolution of innate immunity through co-option of endogenous retroviruses. Science 351, 1083-1087.

Cipriani, C., Pitzianti, M.B., Matteucci, C., D'Agati, E., Miele, M.T., Rapaccini, V., Grelli, S., Curatolo, P., Sinibaldi-Vallebona, P., Pasini, A., et al. (2018). The decrease in human endogenous retrovirus- $\mathrm{H}$ activity runs in parallel with improvement in ADHD symptoms in patients undergoing methylphenidate therapy. Int. J. Mol. Sci. 19, 3286.

Conti, A., Rota, F., Ragni, E., Favero, C., Motta, V., Lazzari, L., Bollati, V., Fustinoni, S., and Dieci, G. (2016). Hydroquinone induces DNA hypomethylation-independent overexpression of retroelements in human leukemia and hematopoietic stem cells. Biochem. Biophys. Res. Commun. 474, 691-695.

Contreras-Galindo, R., Kaplan, M.H., Leissner, P., Verjat, T., Ferlenghi, I., Bagnoli, F., Giusti, F., Dosik, M.H., Hayes, D.F., Gitlin, S.D., et al. (2008). Human endogenous retrovirus K (HML-2) elements in the plasma of people with lymphoma and breast cancer. J. Virol. 82, 9329-9336.

Contreras-Galindo, R., López, P., Vélez, R., and Yamamura, Y. (2007). HIV1 infection increases the expression of human endogenous retroviruses type K (HERV-K) in vitro. AIDS Res. Hum. Retroviruses 23, 116-122.

D'Agati, E., Pitzianti, M., Balestrieri, E., Matteucci, C., Sinibaldi Vallebona, P., and Pasini, A. (2016). First evidence of HERV-H transcriptional activity reduction after methylphenidate treatment in a young boy with ADHD. New Microbiol. 39, 237-239.

Dai, L., Del Valle, L., Miley, W., Whitby, D., Ochoa, A.C., Flemington, E.K., and Qin, Z. (2018). Transactivation of human endogenous retrovirus K (HERV-K) by KSHV promotes Kaposi's sarcoma development. Oncogene 37, 4534-4545.

Dechaumes, A., Bertin, A., Sane, F., Levet, S., Varghese, J., Charvet, B., Gmyr, V., Kerr-Conte, J., Pierquin, J., Arunkumar, G., et al. (2020). Coxsackievirus-B4 infection can induce the expression of human endogenous retrovirus W in primary cells. Microorganisms 8, 1335.

Denne, M., Sauter, M., Armbruester, V., Licht, J.D., Roemer, K., and MuellerLantzsch, N. (2007). Physical and functional interactions of human endogenous retrovirus proteins $\mathrm{Np} 9$ and rec with the promyelocytic leukemia zinc finger protein. J. Virol. 81, 5607-5616.

Denner, J. (2016). How active are porcine endogenous retroviruses (PERVs)? Viruses 8, 215.

Depil, S., Roche, C., Dussart, P., and Prin, L. (2002). Expression of a human endogenous retrovirus, HERV-K, in the blood cells of leukemia patients. Leukemia 16, 254-259.

Dewannieux, M. and Heidmann, T. (2013). Endogenous retroviruses: acquisition, amplification and taming of genome invaders. Curr. Opin. Virol. 3, 646-656.

Dhakal, S. and Lee, Y. (2019). Transient receptor potential channels and metabolism. Mol. Cells 42, 569-578.

Dinsmore, J.H. and Solomon, F. (1991). Inhibition of MAP2 expression affects both morphological and cell division phenotypes of neuronal differentiation. Cell 64, 817-826.

Dolci, M., Favero, C., Tarantini, L., Villani, S., Bregni, M., Signorini, L., Della Valle, A., Crivelli, F., D'Alessandro, S., Ferrante, P., et al. (2020). Human endogenous retroviruses env gene expression and long terminal repeat methylation in colorectal cancer patients. Med. Microbiol. Immunol. 209, 189-199.

Doucet-O'Hare, T.T., DiSanza, B.L., DeMarino, C., Atkinson, A.L., Rosenblum,
J.S., Henderson, L.J., Johnson, K.R., Kowalak, J., Garcia-Montojo, M., Allen, S.J., et al. (2021). SMARCB1 deletion in atypical teratoid rhabdoid tumors results in human endogenous retrovirus K (HML-2) expression. Sci. Rep. $11,12893$.

Dunn, C.A., Medstrand, P., and Mager, D.L. (2003). An endogenous retroviral long terminal repeat is the dominant promoter for human beta1,3-galactosyltransferase 5 in the colon. Proc. Natl. Acad. Sci. U. S. A. $100,12841-12846$

Duperray, A., Barbe, D., Raguenez, G., Weksler, B.B., Romero, I.A., Couraud, P.O., Perron, H., and Marche, P.N. (2015). Inflammatory response of endothelial cells to a human endogenous retrovirus associated with multiple sclerosis is mediated by TLR4. Int. Immunol. 27, 545-553.

Durnaoglu, S., Kim, H.S., Ahnn, J., and Lee, S.K. (2020). Human Endogenous Retrovirus K (HERV-K) can drive gene expression as a promoter in Caenorhabditis elegans. BMB Rep. 53, 521-526.

Escalera-Zamudio, M. and Greenwood, A.D. (2016). On the classification and evolution of endogenous retrovirus: human endogenous retroviruses may not be 'human' after all. APMIS 124, 44-51.

Etchberger, J.F., Lorch, A., Sleumer, M.C., Zapf, R., Jones, S.J., Marra, M.A., Holt, R.A., Moerman, D.G., and Hobert, O. (2007). The molecular signature and cis-regulatory architecture of a $C$. elegans gustatory neuron. Genes Dev. 21, 1653-1674.

Firouzi, R., Rolland, A., Michel, M., Jouvin-Marche, E., Hauw, J.J., MalcusVocanson, C., Lazarini, F., Gebuhrer, L., Seigneurin, J.M., Touraine, J.L., et al. (2003). Multiple sclerosis-associated retrovirus particles cause T lymphocyte-dependent death with brain hemorrhage in humanized SCID mice model. J. Neurovirol. 9, 79-93.

Fischer, S., Echeverria, N., Cristina, J., and Moreno, P. (2016). Human endogenous retrovirus: their relationship with hematological diseases. J. Leuk. (Los Angel.) 4, 217.

Florl, A.R., Löwer, R., Schmitz-Dräger, B.J., and Schulz, W.A. (1999). DNA methylation and expression of LINE- 1 and HERV-K provirus sequences in urothelial and renal cell carcinomas. Br. J. Cancer 80, 1312-1321.

Frank, O., Giehl, M., Zheng, C., Hehlmann, R., Leib-Mösch, C., and Seifarth, W. (2005). Human endogenous retrovirus expression profiles in samples from brains of patients with schizophrenia and bipolar disorders. J. Virol. 79, 10890-10901.

Frank, O., Jones-Brando, L., Leib-Mosch, C., Yolken, R., and Seifarth, W. (2006). Altered transcriptional activity of human endogenous retroviruses in neuroepithelial cells after infection with Toxoplasma gondii. J. Infect. Dis. 194, 1447-1449.

Freimanis, G., Hooley, P., Ejtehadi, H.D., Ali, H.A., Veitch, A., Rylance, P.B., Alawi, A., Axford, J., Nevill, A., Murray, P.G., et al. (2010). A role for human endogenous retrovirus- $\mathrm{K}(\mathrm{HML}-2)$ in rheumatoid arthritis: investigating mechanisms of pathogenesis. Clin. Exp. Immunol. 160, 340-347.

Fries, G.R., Walss-Bass, C., Bauer, M.E., and Teixeira, A.L. (2019). Revisiting inflammation in bipolar disorder. Pharmacol. Biochem. Behav. 177, 12-19.

Fuchs, N.V., Kraft, M., Tondera, C., Hanschmann, K.M., Löwer, J., and Löwer, R. (2011). Expression of the human endogenous retrovirus (HERV) group HML-2/HERV-K does not depend on canonical promoter elements but is regulated by transcription factors Sp1 and Sp3. J. Virol. 85, 3436-3448.

Fuentes, D.R., Swigut, T., and Wysocka, J. (2018). Systematic perturbation of retroviral LTRs reveals widespread long-range effects on human gene regulation. Elife 7, e35989.

Gabriel, U., Steidler, A., Trojan, L., Michel, M.S., Seifarth, W., and Fabarius, A. (2010). Smoking increases transcription of human endogenous retroviruses in a newly established in vitro cell model and in normal urothelium. AIDS Res. Hum. Retroviruses 26, 883-888.

Galli, U.M., Sauter, M., Lecher, B., Maurer, S., Herbst, H., Roemer, K., and Mueller-Lantzsch, N. (2005). Human endogenous retrovirus rec interferes with germ cell development in mice and may cause carcinoma in situ, the predecessor lesion of germ cell tumors. Oncogene 24, 3223-3228. 
Gao, Y., Yu, X.F., and Chen, T. (2021). Human endogenous retroviruses in cancer: expression, regulation and function. Oncol. Lett. 21, 121.

Garcia-Montojo, M. and Nath, A. (2021). HERV-W envelope expression in blood leukocytes as a marker of disease severity of COVID-19. EBioMedicine 67, 103363.

Garcia-Montojo, M., Doucet-O'Hare, T., Henderson, L., and Nath, A. (2018). Human endogenous retrovirus-K (HML-2): a comprehensive review. Crit. Rev. Microbiol. 44, 715-738.

Garson, J.A., Tuke, P.W., Giraud, P., Paranhos-Baccala, G., and Perron, H. (1998). Detection of virion-associated MSRV-RNA in serum of patients with multiple sclerosis. Lancet 351, 33.

Giménez-Orenga, K. and Oltra, E. (2021). Human endogenous retrovirus as therapeutic targets in neurologic disease. Pharmaceuticals (Basel) 14, 495.

Gutiérrez-Lovera, C., Vázquez-Ríos, A.J., Guerra-Varela, J., Sánchez, L., and de la Fuente, M. (2017). The potential of zebrafish as a model organism for improving the translation of genetic anticancer nanomedicines. Genes (Basel) 8, 349.

Goering, W., Ribarska, T., and Schulz, W.A. (2011). Selective changes of retroelement expression in human prostate cancer. Carcinogenesis 32, 1484-1492.

Goldsmith, D.R., Rapaport, M.H., and Miller, B.J. (2016). A meta-analysis of blood cytokine network alterations in psychiatric patients: comparisons between schizophrenia, bipolar disorder and depression. Mol. Psychiatry 21, 1696-1709.

Gorrini, C., Squatrito, M., Luise, C., Syed, N., Perna, D., Wark, L., Martinato, F., Sardella, D., Verrecchia, A., Bennett, S., et al. (2007). Tip60 is a haploinsufficient tumour suppressor required for an oncogene-induced DNA damage response. Nature 448, 1063-1067.

Griffiths, D.J. (2001). Endogenous retroviruses in the human genome sequence. Genome Biol. 2, REVIEWS1017.

Gröger, V., Emmer, A., Staege, M.S., and Cynis, H. (2021). Endogenous retroviruses in nervous system disorders. Pharmaceuticals (Basel) 14, 70.

Gutierrez, K., Dicks, N., Glanzner, W., Agellon, L., and Bordignon, V. (2015). Efficacy of the porcine species in biomedical research. Front. Genet. 6, 293.

Hamilton, N., Clarke, A., Isles, H., Carson, E., Levraud, J.P., and Renshaw, S.A. (2021). A zebrafish reporter line reveals immune and neuronal expression of endogenous retrovirus. BioRxiv, https://doi. org/10.1101/2021.01.21.427598

Hanke, K., Chudak, C., Kurth, R., and Bannert, N. (2013). The Rec protein of HERV-K(HML-2) upregulates androgen receptor activity by binding to the human small glutamine-rich tetratricopeptide repeat protein (hSGT). Int. J. Cancer 132, 556-567.

Hayward, A., Cornwallis, C.K., and Jern, P. (2015). Pan-vertebrate comparative genomics unmasks retrovirus macroevolution. Proc. Natl. Acad. Sci. U. S. A. 112, 464-469.

Hayward, A., Grabherr, M., and Jern, P. (2013). Broad-scale phylogenomics provides insights into retrovirus-host evolution. Proc. Natl. Acad. Sci. U. S. A. 110, 20146-20151.

Herbst, H., Sauter, M., and Mueller-Lantzsch, N. (1996). Expression of human endogenous retrovirus $\mathrm{K}$ elements in germ cell and trophoblastic tumors. Am. J. Pathol. 149, 1727-1735.

Hohenadl, C., Germaier, H., Walchner, M., Hagenhofer, M., Herrmann, M., Stürzl, M., Kind, P., Hehlmann, R., Erfle, V., and Leib-Mösch, C. (1999). Transcriptional activation of endogenous retroviral sequences in human epidermal keratinocytes by UVB irradiation. J. Invest. Dermatol. 113, 587594.

Hohn, O., Hanke, K., and Bannert, N. (2013). HERV-K(HML-2), the best preserved family of HERVs: endogenization, expression, and implications in health and disease. Front. Oncol. 3, 246.
Howe, K., Clark, M.D., Torroja, C.F., Torrance, J., Berthelot, C., Muffato, M., Collins, J.E., Humphray, S., McLaren, K., Matthews, L., et al. (2013). The zebrafish reference genome sequence and its relationship to the human genome. Nature 496, 498-503.

Huang, W., Li, S., Hu, Y., Yu, H., Luo, F., Zhang, Q., and Zhu, F. (2011). Implication of the env gene of the human endogenous retrovirus $W$ family in the expression of BDNF and DRD3 and development of recentonset schizophrenia. Schizophr. Bull. 37, 988-1000.

Huang, Y., Kim, J.K., Do, D.V., Lee, C., Penfold, C.A., Zylicz, J.J., Marioni, J.C., Hackett, J.A., and Surani, M.A. (2017). Stella modulates transcriptional and endogenous retrovirus programs during maternal-to-zygotic transition. Elife 6, e22345

Jennings, B.H. (2011). Drosophila - a versatile model in biology \& medicine. Mater. Today (Kidlington) 14, 190-195.

Jo, J.O., Kang, Y.J., Ock, M.S., Song, K.S., Jeong, M.J., Jeong, S.J., Choi, Y.H., Ko, E.J., Leem, S.H., Kim, S., et al. (2016). Expression profiles of HERV-K Env protein in normal and cancerous tissues. Genes Genomics 38, 91-107.

Jönsson, M.E., Garza, R., Sharma, Y., Petri, R., Södersten, E., Johansson, J.G., Johansson, P.A., Atacho, D.A., Pircs, K., Madsen, S., et al. (2021). Activation of endogenous retroviruses during brain development causes an inflammatory response. EMBO J. 40, e106423.

Jung, G.T., Kim, K.P., and Kim, K. (2020a). How to interpret and integrate multi-omics data at systems level. Anim. Cells Syst. (Seoul) 24, 1-7.

Jung, J., Choi, I., Ro, H., Huh, T.L., Choe, J., and Rhee, M. (2020b). march5 governs the convergence and extension movement for organization of the telencephalon and diencephalon in zebrafish embryos. Mol. Cells 43, 76-85.

Jung, J., Udhaya Kumar, S., Choi, I., Huh, T.L., and Rhee, M. (2019). Znf76 is associated with development of the eyes, midbrain, MHB, and hindbrain in zebrafish embryos. Anim. Cells Syst. (Seoul) 23, 26-31.

Kannan, P., Buettner, R., Pratt, D.R., and Tainsky, M.A. (1991). Identification of a retinoic acid-inducible endogenous retroviral transcript in the human teratocarcinoma-derived cell line PA-1. J. Virol. 65, 6343-6348.

Karimi, A., Sheervalilou, R., and Kahroba, H. (2019). A new insight on activation of human endogenous retroviruses (HERVs) in malignant melanoma upon exposure to CuSO4. Biol. Trace Elem. Res. 191, 70-74.

Karlsson, H., Schröder, J., Bachmann, S., Bottmer, C., and Yolken, R.H. (2004). HERV-W-related RNA detected in plasma from individuals with recent-onset schizophrenia or schizoaffective disorder. Mol. Psychiatry 9, $12-13$

Kassiotis, G. (2014). Endogenous retroviruses and the development of cancer. J. Immunol. 192, 1343-1349.

Katoh, I., Mírová, A., Kurata, S., Murakami, Y., Horikawa, K., Nakakuki, N., Sakai, T., Hashimoto, K., Maruyama, A., Yonaga, T., et al. (2011). Activation of the long terminal repeat of human endogenous retrovirus $K$ by melanoma-specific transcription factor MITF-M. Neoplasia 13, 1081-1092.

Katsumata, K., Ikeda, H., Sato, M., Ishizu, A., Kawarada, Y., Kato, H., Wakisaka, A., Koike, T., and Yoshiki, T. (1999). Cytokine regulation of env gene expression of human endogenous retrovirus- $R$ in human vascular endothelial cells. Clin. Immunol. 93, 75-80.

Kim, D.Y., Moon, S.H., Han, J.H., Kim, M.J., Oh, S.J., Bharti, D., Lee, S.H., Park, J.K., Rho, G.J., and Jeon, B.G. (2020). Terminal differentiation into adipocyte and growth inhibition by PPAR $\gamma$ activation in human A549 lung adenocarcinoma cells. Anim. Cells Syst. (Seoul) 24, 329-340.

Kim, S.H., Jung, H., Ahnn, J., and Lee, S.K. (2019). Calcineurin tax-6 regulates male ray development and counteracts with kin-29 kinase in Caenorhabditis elegans. Anim. Cells Syst. (Seoul) 23, 399-406.

Kim, Y.J., Kim, K., Seo, S.Y., Yu, J., Kim, I.H., Kim, H.J., Park, C.K., Lee, K.H., Choi, J., Song, M.S., et al. (2021). Time-sequential change in immunerelated gene expression after irradiation in glioblastoma: next-generation sequencing analysis. Anim. Cells Syst. (Seoul) 25, 245-254. 
Knössl, M., Löwer, R., and Löwer, J. (1999). Expression of the human endogenous retrovirus HTDV/HERV-K is enhanced by cellular transcription factor YY1. J. Virol. 73, 1254-1261.

Ko, E.J., Ock, M.S., Choi, Y.H., lovanna, J.L., Mun, S., Han, K., Kim, H.S., and Cha, H.J. (2021a). Human endogenous retrovirus (HERV)-K env gene knockout affects tumorigenic characteristics of nupr1 gene in DLD-1 colorectal cancer cells. Int. J. Mol. Sci. 22, 3941.

Ko, E.J., Song, K.S., Ock, M.S., Choi, Y.H., Kim, S., Kim, H.S., and Cha, H.J. (2021b). Expression profiles of human endogenous retrovirus (HERV)-K and HERV-R Env proteins in various cancers. BMB Rep. 54, 368-373.

Komurian-Pradel, F., Paranhos-Baccala, G., Bedin, F., Ounanian-Paraz, A. Sodoyer, M., Ott, C., Rajoharison, A., Garcia, E., Mallet, F., Mandrand, B., et al. (1999). Molecular cloning and characterization of MSRV-related sequences associated with retrovirus-like particles. Virology 260, 1-9.

Kristensen, M.K. and Christensen, T. (2021). Regulation of the expression of human endogenous retroviruses: elements in fetal development and a possible role in the development of cancer and neurological diseases. APMIS 129, 241-253.

Krug, L., Chatterjee, N., Borges-Monroy, R., Hearn, S., Liao, W.W., Morrill, K., Prazak, L., Rozhkov, N., Theodorou, D., Hammell, M., et al. (2017). Retrotransposon activation contributes to neurodegeneration in a Drosophila TDP-43 model of ALS. PLoS Genet. 13, e1006635.

Kuzmich, N.N., Sivak, K.V., Chubarev, V.N., Porozov, Y.B., SavateevaLyubimova, T.N., and Peri, F. (2017). TLR4 signaling pathway modulators as potential therapeutics in inflammation and sepsis. Vaccines (Basel) 5 , 34.

Lamprecht, B., Walter, K., Kreher, S., Kumar, R., Hummel, M., Lenze, D., Köchert, K., Bouhlel, M.A.r, Richter, J., Soler, E., et al. (2010). Derepression of an endogenous long terminal repeat activates the CSF1R proto-oncogene in human lymphoma. Nat. Med. 16, 571-579, 1p following 579.

Lee, G.Y., Sohn, J., and Lee, S.J.V. (2021a). Combinatorial approach using Caenorhabditis elegans and mammalian systems for aging research. Mol. Cells 44, 425-432.

Lee, H., Yoon, D.E., and Kim, K. (2020b). Genome editing methods in animal models. Anim. Cells Syst. (Seoul) 24, 8-16.

Lee, H.E., Park, S.J., Huh, J.W., Imai, H., and Kim, H.S. (2020a). Enhancer function of microRNA-3681 derived from long terminal repeats represses the activity of variable number tandem repeats in the $3^{\prime}$ UTR of SHISA7. Mol. Cells 43, 607-618.

Lee, S.H. and Kim, E.Y. (2021). Short-term maintenance on a high-sucrose diet alleviates aging-induced sleep fragmentation in drosophila. Anim. Cells Syst. (Seoul) 2021 Nov 3 [Epub]. https://doi.org/10.1080/19768354.2 021.1997801

Lee, W., Mariappan, R., De, K., and Ohn, T. (2021b). Loss of MeCP2 causes subtle alteration in dendritic arborization of retinal ganglion cells. Anim. Cells Syst. (Seoul) 25, 102-109.

Lee, W.C., Kim, D.Y., Kim, M.J., Lee, H.J., Bharti, D., Lee, S.H., Kang, Y.H., Rho, G.J., and Jeon, B.G. (2019a). Delay of cell growth and loss of stemness by inhibition of reverse transcription in human mesenchymal stem cells derived from dental tissue. Anim. Cells Syst. (Seoul) 23, 335-345.

Lee, W.J., Kwun, H.J., Kim, H.S., and Jang, K.L. (2003). Activation of the human endogenous retrovirus $\mathrm{W}$ long terminal repeat by herpes simplex virus type 1 immediate early protein 1 . Mol. Cells $15,75-80$.

Lee, Y., Kang, H., Jin, C., Zhang, Y., Kim, Y., and Han, K. (2019b). Transcriptome analyses suggest minimal effects of Shank3 dosage on directional gene expression changes in the mouse striatum. Anim. Cells Syst. (Seoul) 23, 270-274.

Lee, Y., Kim, D., and Lee, C.J. (2020c). Suppressive effects of valproic acid on caudal fin regeneration in adult zebrafish. Anim. Cells Syst. (Seoul) 24, 349-358.

Lee, Y., Lee, M., Lee, S.W., Choi, N.Y., Ham, S., Lee, H.J., Ko, K., and Ko, K. (2019c). Reprogramming of spermatogonial stem cells into pluripotent stem cells in the spheroidal state. Anim. Cells Syst. (Seoul) 23, 392-398.

Lemaître, C., Tsang, J., Bireau, C., Heidmann, T., and Dewannieux, M. (2017). A human endogenous retrovirus-derived gene that can contribute to oncogenesis by activating the ERK pathway and inducing migration and invasion. PLoS Pathog. 13, e1006451.

Levet, S., Medina, J., Joanou, J., Demolder, A., Queruel, N., Réant, K., Normand, M., Seffals, M., Dimier, J., Germi, R., et al. (2017). An ancestral retroviral protein identified as a therapeutic target in type- 1 diabetes. JCI Insight 2, e94387.

Levine, E. and Lee, K.S. (2020). Microfluidic approaches for Caenorhabditis elegans research. Anim. Cells Syst. (Seoul) 24, 311-320.

Li, M., Radvanyi, L., Yin, B., Rycaj, K., Li, J., Chivukula, R., Lin, K., Lu, Y., Shen, J., Chang, D.Z., et al. (2017). Downregulation of human endogenous retrovirus type K (HERV-K) viral env RNA in pancreatic cancer cells decreases cell proliferation and tumor growth. Clin. Cancer Res. 23, 58925911.

Li, S., Liu, Z.C., Yin, S.J., Chen, Y.T., Yu, H.L., Zeng, J., Zhang, Q., and Zhu, F. (2013). Human endogenous retrovirus $W$ family envelope gene activates the small conductance $\mathrm{Ca} 2+$-activated $\mathrm{K}+$ channel in human neuroblastoma cells through CREB. Neuroscience 247, 164-174.

Li, W., Lee, M.H., Henderson, L., Tyagi, R., Bachani, M., Steiner, J., Campanac, E., Hoffman, D.A., von Geldern, G., Johnson, K., et al. (2015). Human endogenous retrovirus- $\mathrm{K}$ contributes to motor neuron disease. Sci. Transl. Med. 7, 307ra153.

Li, Z., Sheng, T., Wan, X., Liu, T., Wu, H., and Dong, J. (2010). Expression of HERV-K correlates with status of MEK-ERK and p16INK4A-CDK4 pathways in melanoma cells. Cancer Invest. 28, 1031-1037.

Madeira, A., Burgelin, I., Perron, H., Curtin, F., Lang, A.B., and Faucard, R. (2016). MSRV envelope protein is a potent, endogenous and pathogenic agonist of human toll-like receptor 4: relevance of GNbAC1 in multiple sclerosis treatment. J. Neuroimmunol. 291, 29-38.

Mager, D.L. and Medstrand, P. (2005). Retroviral repeat sequences. eLS 2005 Sep 23. https://doi.org/10.1038/npg.els.0005062

Mameli, G., Erre, G.L., Caggiu, E., Mura, S., Cossu, D., Bo, M., Cadoni, M.L., Piras, A., Mundula, N., Colombo, E., et al. (2017). Identification of a HERV-K env surface peptide highly recognized in Rheumatoid Arthritis (RA) patients: a cross-sectional case-control study. Clin. Exp. Immunol. 189, 127-131.

Manghera, M., Ferguson-Parry, J., Lin, R., and Douville, R.N. (2016). NF$\kappa B$ and IRF1 induce endogenous retrovirus $K$ expression via interferonstimulated response elements in its 5 ' long terminal repeat. J. Virol. 90, 9338-9349.

Martin, M.A., Bryan, T., Rasheed, S., and Khan, A.S. (1981). Identification and cloning of endogenous retroviral sequences present in human DNA. Proc. Natl. Acad. Sci. U. S. A. 78, 4892-4896.

Mattera, L., Escaffit, F., Pillaire, M.J., Selves, J., Tyteca, S., Hoffmann, J.S., Gourraud, P.A., Chevillard-Briet, M., Cazaux, C., and Trouche, D. (2009). The p400/Tip60 ratio is critical for colorectal cancer cell proliferation through DNA damage response pathways. Oncogene 28, 1506-1517.

Mayer, J., Harz, C., Sanchez, L., Pereira, G.C., Maldener, E., Heras, S.R., Ostrow, L.W., Ravits, J., Batra, R., Meese, E., et al. (2018). Transcriptional profiling of HERV-K(HML-2) in amyotrophic lateral sclerosis and potential implications for expression of HML-2 proteins. Mol. Neurodegener. 13, 39.

Meneely, P.M., Dahlberg, C.L., and Rose, J.K. (2019). Working with worms: Caenorhabditis elegans as a model organism. Curr. Protoc. Essent. Lab. Tech. 19, e35.

Menendez, L., Benigno, B.B., and McDonald, J.F. (2004). L1 and HERV-W retrotransposons are hypomethylated in human ovarian carcinomas. Mol. Cancer 3, 12. 
Misiak, B., Stańczykiewicz, B., Kotowicz, K., Rybakowski, J.K., Samochowiec, J., and Frydecka, D. (2018). Cytokines and C-reactive protein alterations with respect to cognitive impairment in schizophrenia and bipolar disorder: a systematic review. Schizophr. Res. 192, 16-29.

Mitsuhashi, S., Nakagawa, S., Sasaki-Honda, M., Sakurai, H., Frith, M.C., and Mitsuhashi, H. (2021). Nanopore direct RNA sequencing detects DUX4activated repeats and isoforms in human muscle cells. Hum. Mol. Genet. $30,552-563$

Montesion, M., Williams, Z.H., Subramanian, R.P., Kuperwasser, C., and Coffin, J.M. (2018). Promoter expression of HERV-K (HML-2) provirusderived sequences is related to LTR sequence variation and polymorphic transcription factor binding sites. Retrovirology 15, 57 .

Moon, Y., Moon, R., Roh, H., Chang, S., Lee, S., and Park, H. (2020). HIF-1 $\alpha-$ dependent induction of carboxypeptidase A4 and carboxypeptidase $\mathrm{E}$ in hypoxic human adipose-derived stem cells. Mol. Cells 43, 945-952.

Moses, K., Ellis, M.C., and Rubin, G.M. (1989). The glass gene encodes a zinc-finger protein required by Drosophila photoreceptor cells. Nature $340,531-536$.

Mullins, C.S. and Linnebacher, M. (2012). Human endogenous retroviruses and cancer: causality and therapeutic possibilities. World J. Gastroenterol. 18, 6027-6035.

Nakagawa, K., Brusic, V., McColl, G., and Harrison, L.C. (1997). Direct evidence for the expression of multiple endogenous retroviruses in the synovial compartment in rheumatoid arthritis. Arthritis Rheum. 40, 627638

Nakkuntod, J., Sukkapan, P., Avihingsanon, Y., Mutirangura, A., and Hirankarn, N. (2013). DNA methylation of human endogenous retrovirus in systemic lupus erythematosus. J. Hum. Genet. 58, 241-249.

Nellåker, C., Yao, Y., Jones-Brando, L., Mallet, F., Yolken, R.H., and Karlsson, $H$. (2006). Transactivation of elements in the human endogenous retrovirus W family by viral infection. Retrovirology 3, 44 .

Nelson, P.N. (1995). Retroviruses in rheumatic diseases. Ann. Rheum. Dis. $54,441-442$

Nemes, K. and Frühwald, M.C. (2018). Emerging therapeutic targets for the treatment of malignant rhabdoid tumors. Expert Opin. Ther. Targets 22, 365-379.

Nguyen, T.D., Davis, J., Eugenio, R.A., and Liu, Y. (2019). Female sex hormones activate human endogenous retrovirus type $K$ through the OCT4 transcription factor in T47D breast cancer cells. AIDS Res. Hum. Retroviruses 35, 348-356.

Oh, S. and Park, J.T. (2019). Zebrafish model of KRAS-initiated pancreatic endocrine tumor. Anim. Cells Syst. (Seoul) 23, 209-218.

Ohgaki, H. and Kleihues, P. (2005). Epidemiology and etiology of gliomas. Acta Neuropathol. 109, 93-108.

Okada, M., Ogasawara, H., Kaneko, H., Hishikawa, T., Sekigawa, I., Hashimoto, H., Maruyama, N., Kaneko, Y., and Yamamoto, N. (2002). Role of DNA methylation in transcription of human endogenous retrovirus in the pathogenesis of systemic lupus erythematosus. J. Rheumatol. 29, 1678-1682.

Ono, M., Kawakami, M., and Ushikubo, H. (1987). Stimulation of expression of the human endogenous retrovirus genome by female steroid hormones in human breast cancer cell line T47D. J. Virol. 61, 20592062.

Ostrom, Q.T., Gittleman, H., Fulop, J., Liu, M., Blanda, R., Kromer, C. Wolinsky, Y., Kruchko, C., and Barnholtz-Sloan, J.S. (2015). CBTRUS statistical report: primary brain and central nervous system tumors diagnosed in the United States in 2008-2012. Neuro Oncol. 17 Suppl 4 , iv1-iv62.

Ovejero, T., Sadones, O., Sánchez-Fito, T., Almenar-Pérez, E., Espejo, J.A. Martín-Martínez, E., Nathanson, L., and Oltra, E. (2020). Activation of transposable elements in immune cells of fibromyalgia patients. Int. J.
Mol. Sci. 21, 1366 .

Padmanabhan Nair, V., Liu, H., Ciceri, G., Jungverdorben, J., Frishman, G., Tchieu, J., Cederquist, G.Y., Rothenaigner, I., Schorpp, K., Klepper, L., et al. (2021). Activation of HERV-K(HML-2) disrupts cortical patterning and neuronal differentiation by increasing NTRK3. Cell Stem Cell 28, 15661581.e8.

Payer, B., Saitou, M., Barton, S.C., Thresher, R., Dixon, J.P., Zahn, D. Colledge, W.H., Carlton, M.B., Nakano, T., and Surani, M.A. (2003). Stella is a maternal effect gene required for normal early development in mice. Curr. Biol. 13, 2110-2117.

Perron, H., Dougier-Reynaud, H.L., Lomparski, C., Popa, I., Firouzi, R., Bertrand, J.B., Marusic, S., Portoukalian, J., Jouvin-Marche, E., Villiers, C.L., et al. (2013). Human endogenous retrovirus protein activates innate immunity and promotes experimental allergic encephalomyelitis in mice. Plos One 8, e80128.

Perron, H., Hamdani, N., Faucard, R., Lajnef, M., Jamain, S., DabanHuard, C., Sarrazin, S., LeGuen, E., Houenou, J., Delavest, M., et al. (2012). Molecular characteristics of Human Endogenous Retrovirus type-W in schizophrenia and bipolar disorder. Transl. Psychiatry 2, e201.

Perron, H., Mekaoui, L., Bernard, C., Veas, F., Stefas, I., and Leboyer, M. (2008). Endogenous retrovirus type W GAG and envelope protein antigenemia in serum of schizophrenic patients. Biol. Psychiatry 64, 10191023.

Pi, W., Yang, Z., Wang, J., Ruan, L., Yu, X., Ling, J., Krantz, S., Isales, C., Conway, S.J., Lin, S., et al. (2004). The LTR enhancer of ERV-9 human endogenous retrovirus is active in oocytes and progenitor cells in transgenic zebrafish and humans. Proc. Natl. Acad. Sci. U. S. A. 101, 805810.

Quelle, D.E., Zindy, F., Ashmun, R.A., and Sherr, C.J. (1995). Alternative reading frames of the INK4a tumor suppressor gene encode two unrelated proteins capable of inducing cell cycle arrest. Cell 83, 993-1000.

Rajagopalan, D., Tirado-Magallanes, R., Bhatia, S.S., Teo, W.S., Sian, S., Hora, S., Lee, K.K., Zhang, Y., Jadhav, S.P., Wu, Y., et al. (2018). TIP60 represses activation of endogenous retroviral elements. Nucleic Acids Res. 46, 9456-9470

Ramsoondar, J., Vaught, T., Ball, S., Mendicino, M., Monahan, J., Jobst, P., Vance, A., Duncan, J., Wells, K., and Ayares, D. (2009). Production of transgenic pigs that express porcine endogenous retrovirus small interfering RNAs. Xenotransplantation 16, 164-180.

Rasmussen, H.B., Geny, C., Deforges, L., Perron, H., Tourtelotte, W., Heltberg, A., and Clausen, J. (1995). Expression of endogenous retroviruses in blood mononuclear cells and brain tissue from multiple sclerosis patients. Mult. Scler. 1, 82-87.

Reiche, J., Pauli, G., and Ellerbrok, H. (2010). Differential expression of human endogenous retrovirus $\mathrm{K}$ transcripts in primary human melanocytes and melanoma cell lines after UV irradiation. Melanoma Res. 20, 435-440.

Rimal, S., Sang, J., Dhakal, S., and Lee, Y. (2020). Cucurbitacin B activates bitter-sensing gustatory receptor neurons via gustatory receptor $33 a$ in Drosophila melanogaster. Mol. Cells 43, 530-538.

Rodriguez-Pintó, I., Agmon-Levin, N., Howard, A., and Shoenfeld, Y. (2014). Fibromyalgia and cytokines. Immunol. Lett. 161, 200-203.

Rolland, A., Jouvin-Marche, E., Viret, C., Faure, M., Perron, H., and Marche, P.N. (2006). The envelope protein of a human endogenous retrovirus-W family activates innate immunity through CD14/TLR4 and promotes Th1like responses. J. Immunol. 176, 7636-7644.

Romao, M., Peracoli, J.C., Bannwart-Castro, C.F., Medeiros, L.T., Weel, I.C., Borges, V.T., Golim, M.A., and Peracoli, M.T. (2012). PP063. TLR4 expression and pro-inflammatory cytokine production by peripheral blood monocytes from preeclamptic women. Pregnancy Hypertens. 2, 276.

Saito, T., Mihira, N., Matsuba, Y., Sasaguri, H., Hashimoto, S., Narasimhan, 
S., Zhang, B., Murayama, S., Higuchi, M., Lee, V.M.Y., et al. (2019). Humanization of the entire murine Mapt gene provides a murine model of pathological human tau propagation. J. Biol. Chem. 294, 12754-12765.

Santoni, F.A., Guerra, J., and Luban, J. (2012). HERV-H RNA is abundant in human embryonic stem cells and a precise marker for pluripotency. Retrovirology 9, 111.

Schanab, O., Humer, J., Gleiss, A., Mikula, M., Sturlan, S., Grunt, S., Okamoto, I., Muster, T., Pehamberger, H., and Waltenberger, A. (2011). Expression of human endogenous retrovirus $\mathrm{K}$ is stimulated by ultraviolet radiation in melanoma. Pigment Cell Melanoma Res. 24, 656-665.

Serafino, A., Balestrieri, E., Pierimarchi, P., Matteucci, C., Moroni, G., Oricchio, E., Rasi, G., Mastino, A., Spadafora, C., Garaci, E., et al. (2009). The activation of human endogenous retrovirus $K$ (HERV-K) is implicated in melanoma cell malignant transformation. Exp. Cell Res. 315, 849-862.

Shah, M. and Woo, H.G. (2021). Molecular perspectives of SARS-CoV-2: pathology, immune evasion, and therapeutic interventions. Mol. Cells 44 , 408-421.

Siebenthall, K.T., Miller, C.P., Vierstra, J.D., Mathieu, J., Tretiakova, M., Reynolds, A., Sandstrom, R., Rynes, E., Haugen, E., Johnson, A., et al. (2019). Integrated epigenomic profiling reveals endogenous retrovirus reactivation in renal cell carcinoma. EBioMedicine 41, 427-442.

Stengel, S., Fiebig, U., Kurth, R., and Denner, J. (2010). Regulation of human endogenous retrovirus- $\mathrm{K}$ expression in melanomas by $\mathrm{CpG}$ methylation. Genes Chromosomes Cancer 49, 401-411.

Strick, R., Ackermann, S., Langbein, M., Swiatek, J., Schubert, S.W., Hashemolhosseini, S., Koscheck, T., Fasching, P.A., Schild, R.L., Beckmann, M.W., et al. (2007). Proliferation and cell-cell fusion of endometrial carcinoma are induced by the human endogenous retroviral Syncytin-1 and regulated by TGF-beta. J. Mol. Med. (Berl.) 85, 23-38.

Sutkowski, N., Chen, G., Calderon, G., and Huber, B.T. (2004). Epstein-Barr virus latent membrane protein LMP-2A is sufficient for transactivation of the human endogenous retrovirus HERV-K18 superantigen. J. Virol. 78 , 7852-7860.

Tanaka, S. (2000). [Molecular and pathological analyses of newly established transgenic rats carrying human endogenous retrovirus gene, ERV3]. Hokkaido Igaku Zasshi 75, 105-116. Japanese.

Tanaka, S., Ikeda, H., Otsuka, N., Yamamoto, Y., Sugaya, T., and Yoshiki, T. (2003). Tissue specific high level expression of a full length human endogenous retrovirus genome transgene, HERV-R, under control of its own promoter in rats. Transgenic Res. 12, 319-328.

Tie, C.H., Fernandes, L., Conde, L., Robbez-Masson, L., Sumner, R.P., Peacock, T., Rodriguez-Plata, M.T., Mickute, G., Gifford, R., Towers, G.J., et al. (2018). KAP1 regulates endogenous retroviruses in adult human cells and contributes to innate immune control. EMBO Rep. 19, e45000.

Tovo, P.A., Garazzino, S., Daprà, V., Pruccoli, G., Calvi, C., Mignone, F., Alliaudi, C., Denina, M., Scolfaro, C., Zoppo, M., et al. (2021). COVID-19 in children: expressions of type I/II/III interferons, TRIM28, SETDB1, and endogenous retroviruses in mild and severe cases. Int. J. Mol. Sci. 22, 7481.

Tugnet, N., Rylance, P., Roden, D., Trela, M., and Nelson, P. (2013). Human endogenous retroviruses (HERVs) and autoimmune rheumatic disease: is there a link? Open Rheumatol. J. 7, 13-21.

Turcanova, V.L., Bundgaard, B., and Höllsberg, P. (2009). Human herpesvirus- $6 \mathrm{~B}$ induces expression of the human endogenous retrovirus K18-encoded superantigen. J. Clin. Virol. 46, 15-19.

Uchida, O., Nakano, H., Koga, M., and Ohshima, Y. (2003). The C. elegans che-1 gene encodes a zinc finger transcription factor required for specification of the ASE chemosensory neurons. Development 130, 12151224.

Vlisidou, I. and Wood, W. (2015). Drosophila blood cells and their role in immune responses. FEBS J. 282, 1368-1382.
Wallace, T.A., Downey, R.F., Seufert, C.J., Schetter, A., Dorsey, T.H., Johnson, C.A., Goldman, R., Loffredo, C.A., Yan, P., Sullivan, F.J., et al. (2014). Elevated HERV-K mRNA expression in PBMC is associated with a prostate cancer diagnosis particularly in older men and smokers. Carcinogenesis 35, 20742083.

Walsh, N.C., Kenney, L.L., Jangalwe, S., Aryee, K.E., Greiner, D.L., Brehm, M.A., and Shultz, L.D. (2017). Humanized mouse models of clinical disease. Annu. Rev. Pathol. 12, 187-215.

Wang-Johanning, F., Liu, J., Rycaj, K., Huang, M., Tsai, K., Rosen, D.G., Chen, D.T., Lu, D.W., Barnhart, K.F., and Johanning, G.L. (2007). Expression of multiple human endogenous retrovirus surface envelope proteins in ovarian cancer. Int. J. Cancer 120, 81-90.

Wang, J., Xie, G., Singh, M., Ghanbarian, A.T., Raskó, T., Szvetnik, A., Cai, H., Besser, D., Prigione, A., Fuchs, N.V., et al. (2014). Primate-specific endogenous retrovirus-driven transcription defines naive-like stem cells. Nature 516, 405-409.

Wang, M., Qiu, Y., Liu, H., Liang, B., Fan, B., Zhou, X., and Liu, D. (2020a). Transcription profile of human endogenous retroviruses in response to dengue virus serotype 2 infection. Virology 544, 21-30.

Wang, T., Medynets, M., Johnson, K.R., Doucet-O'Hare, T.T., DiSanza, B., Li, W., Xu, Y., Bagnell, A., Tyagi, R., Sampson, K., et al. (2020b). Regulation of stem cell function and neuronal differentiation by HERV-K via mTOR pathway. Proc. Natl. Acad. Sci. U. S. A. 117, 17842-17853.

Wang, X., Liu, Z., Wang, P., Li, S., Zeng, J., Tu, X., Yan, Q., Xiao, Z., Pan, M., and Zhu, F. (2018). Syncytin-1, an endogenous retroviral protein, triggers the activation of CRP via TLR3 signal cascade in glial cells. Brain Behav. Immun. 67, 324-334.

Wang, X., Wu, X., Huang, J., Li, H., Yan, Q., and Zhu, F. (2021). Human endogenous retrovirus $W$ family envelope protein (HERV-W env) facilitates the production of TNF- $\alpha$ and IL-10 by inhibiting MyD88s in glial cells. Arch. Virol. 166, 1035-1045.

Wang, X., Zhao, C., Zhang, C., Mei, X., Song, J., Sun, Y., Wu, Z., and Shi, W. (2019). Increased HERV-E clone 4-1 expression contributes to DNA hypomethylation and IL-17 release from CD4(+) T cells via miR-302d/ MBD2 in systemic lupus erythematosus. Cell Commun. Signal. 17, 94.

Wang, Z., Wang, Y., He, Y., Zhang, N., Chang, W., and Niu, Y. (2020c). Aquaporin-1 facilitates proliferation and invasion of gastric cancer cells via GRB7-mediated ERK and Ras activation. Anim. Cells Syst. (Seoul) 24, 253-259.

Yang, Z., Chen, S., Xue, S., Li, X., Sun, Z., Yang, Y., Hu, X., Geng, T., and Cui, $H$. (2018). Generation of Cas9 transgenic zebrafish and their application in establishing an ERV-deficient animal model. Biotechnol. Lett. 40, 15071518.

Young, J.M., Whiddon, J.L., Yao, Z., Kasinathan, B., Snider, L., Geng, L.N., Balog, J., Tawil, R., van der Maarel, S.M., and Tapscott, S.J. (2013). DUX4 binding to retroelements creates promoters that are active in FSHD muscle and testis. PLoS Genet. 9, e1003947.

Yu, H.L., Zhao, Z.K., and Zhu, F. (2013). The role of human endogenous retroviral long terminal repeat sequences in human cancer (Review). Int. J. Mol. Med. 32, 755-762.

Yu, X., Zhu, X., Pi, W., Ling, J., Ko, L., Takeda, Y., and Tuan, D. (2005). The long terminal repeat (LTR) of ERV-9 human endogenous retrovirus binds to NF-Y in the assembly of an active LTR enhancer complex NF-Y/MZF1/ GATA-2. J. Biol. Chem. 280, 35184-35194.

Yuan, Z., Yang, Y., Zhang, N., Soto, C., Jiang, X., An, Z., and Zheng, W.J. (2021). Human endogenous retroviruses in glioblastoma multiforme. Microorganisms 9, 764.

Zhang, Y., Kang, H.R., and Han, K. (2019a). Differential cell-type-expression of CYFIP1 and CYFIP2 in the adult mouse hippocampus. Anim. Cells Syst. (Seoul) 23, 380-383.

Zhang, Y., Li, T., Preissl, S., Amaral, M.L., Grinstein, J.D., Farah, E.N., Destici, E., Qiu, Y., Hu, R., Lee, A.Y., et al. (2019b). Transcriptionally active HERV-H 
Human Endogenous Retroviruses as Gene Expression Regulators Serpen Durnaoglu et al.

retrotransposons demarcate topologically associating domains in human pluripotent stem cells. Nat. Genet. 51, 1380-1388.

Zhou, F., Krishnamurthy, J., Wei, Y., Li, M., Hunt, K., Johanning, G.L., Cooper, L.J., and Wang-Johanning, F. (2015). Chimeric antigen receptor $T$ cells targeting HERV-K inhibit breast cancer and its metastasis through downregulation of Ras. Oncoimmunology 4, e1047582.

Zhou, F., Li, M., Wei, Y., Lin, K., Lu, Y., Shen, J., Johanning, G.L., and WangJohanning, F. (2016). Activation of HERV-K Env protein is essential for tumorigenesis and metastasis of breast cancer cells. Oncotarget 7, 84093-
84117.

Zhou, Y., Liu, L., Liu, Y., Zhou, P., Yan, Q., Yu, H., Chen, X., and Zhu, F. (2021). Implication of human endogenous retrovirus $W$ family envelope in hepatocellular carcinoma promotes MEK/ERK-mediated metastatic invasiveness and doxorubicin resistance. Cell Death Discov. 7, 177.

Zhou, Z., Li, X., Liu, Z., Huang, L., Yao, Y., Li, L., Chen, J., Zhang, R., Zhou, J., Wang, L., et al. (2020). A bromodomain-containing protein 4 (BRD4) inhibitor suppresses angiogenesis by regulating AP-1 expression. Front. Pharmacol. 11, 1043 . 